\title{
5-Arylvinyl-2,2'-bipyridyls: Bright "Push-Pull” Dyes as Components in Fluorescent Indicators for Zinc Ions
}

\author{
Lei Zhu*, Ali H. Younes, ${ }^{\S}$ Zhao Yuan, Ronald J. Clark
}

95 Chieftan Way, Department of Chemistry and Biochemistry, Florida State University, Tallahassee, FL 32306-4390, USA

lzhu@chem.fsu.edu; TEL +1 850645 6813; FAX +1 8506448281

KEYWORDS. bipy; solvent effect; internal charge transfer; zinc; photoinduced electron transfer; Förster resonance energy transfer; fluorescence microscopy

ABSTRACT. This article reviews the zinc(II)-dependent photophysical properties of arylvinylbipyridines (AVBs), a class of fluoroionophores in which 2,2'-bipyridyl and an aryl moiety are electronically conjugated. Zinc(II) binding of an AVB may lead to an emission bathochromic shift of the fluoroionophore without diminishing its fluorescence quantum yield. This observation can be explained using the excited state model of electron donor $-\pi$ bridge electron acceptor "push-pull" fluorophores, in which the bipy moiety acts as an electron acceptor, and zinc(II)-coordination strengthens its electron affinity. The spectral sensitivity of bipy-containing fluoroionophores, such as AVBs, to zinc(II) can be exploited to prepare fluorescent indicators for this ion. In several cases, AVB moieties are incorporated in fluorescent heteroditopic ligands, so that the variation of zinc(II) concentration over a relatively large range 
can be correlated to fluorescence changes in either intensity or color. AVB fluoroionophores are also used to introduce an intramolecular Förster resonance energy transfer (FRET) strategy for creating zinc(II) indicators with high photostability and a narrow emission band, two desired characteristics of dyes used in fluorescence microscopy.

\section{(1) A brief background on 2,2'-bipyridine/metal complexes}

2-2'-Bipyridine (bipy) is a bidentate metal coordination ligand for both early and late transition metal ions $[1,2]$. The metal/bipy complex formation solubilizes the metal ions in organic phases, which leads to methods of (a) metal extraction from aqueous media [3, 4], and (b) homogenous catalysis (e.g., $\left[\mathrm{Cu}(\text { bipy })_{2} \mathrm{Cl}\right]$ in Figure 1, left) in organic phases [5-9]. Metal complexes of bipy and its analogues often bear intense colors (e.g., $\left[\mathrm{Fe}(\text { bipy })_{3}\right] \mathrm{SO}_{4}$ in Figure 1, middle), which has been applied in colorimetric analysis of metal ions [10, 11], and as sun light-absorbing dyes (e.g., N3 dye in Figure 1, right) in sensitized solar cells [12-14]. The colors of these complexes are attributed to metal-to-ligand-charge-transfer (MLCT, or d- $\pi^{*}$ ) absorption transition [15-17], which means that in the lowest excited state of the complex, the metal center is oxidized by the bipy ligand. In order for this to happen, the bipy ligand has to have a low-lying lowestunoccupied molecular orbital (LUMO) to receive an electron from the photo-excited metal center. By installing electron-withdrawing groups such as carboxylate on bipy further lowers its LUMO energy [18], thus enhancing the MLCT transition.

In addition to an oxidizable metal center such as ruthenium(II) or iron(II), an excited organic fluorophore could also offer an electron to the LUMO of bipy, when permitted by the frontier molecular orbital (FMO) energetics and molecular geometries. Similar to the strategy of facilitating MLCT transitions in ruthenium(II) dyes in sensitized solar cells, in which the LUMO 
of bipy is lowered by the electron-withdrawing carboxyl substituents, the electron transfer from an excited organic fluorophore to bipy can also be favored by lowering the LUMO of bipy. This can be done either via covalent bipy functionalization with electron-withdrawing groups, or, more relevant to the topic of this article, via metal coordination.

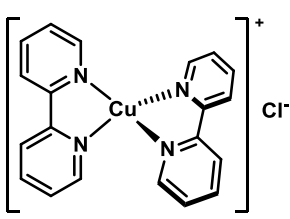

$\left[\mathrm{Cu}^{\prime}(\text { bipy })_{2}\right] \mathrm{Cl}$

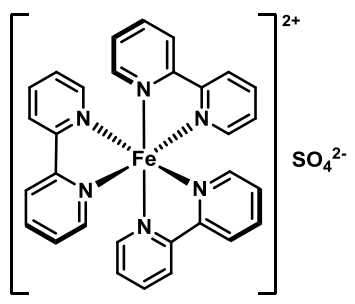

$\left[\mathrm{Fe}^{\prime \prime}(\text { bipy })_{3} \mathrm{SO}_{4}\right.$

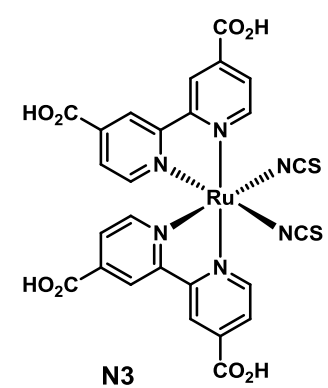

N3

Figure 1. Left: a copper(I)/bipy complex [5] used as an early catalyst in atom transfer radical polymerization (ATRP); middle: an iron(II)/bipy complex that is intensely red; right: a ruthenium(II) complex [14] with a bipy derivative, which is an effective dye in dye-sensitized solar cells. Of the octahedral complexes only one stereoisomer is shown.

In this article, the photophysical properties of selected fluorescent compounds that incorporate bipy as the receptor for zinc(II) ions are reviewed. The utilities of certain compounds as fluorescent indicators for illuminating zinc(II) ions in living mammalian cells using fluorescence microscopy are described. The purpose of this article is to summarize a few lessons on both fundamental photophysics and fluorescence microscopy fronts that we have learned by studying bipy-containing fluorophores. Hopefully these lessons may guide the future studies of fluorescent compounds and their possible utilities as indicators for interesting and important analyte molecules. In addition to the references cited earlier, several other research and review 
articles are listed here for the readers to explore the broader bipy chemistry that is beyond the scope of this article [19-39]. 2,2':6',2''-Terpyridine (terpy) and phenanthroline (phen) have similar metal coordination properties and electron-withdrawing effects to those of bipy. Therefore, a few examples containing terpy or phen are also mentioned.

(a)

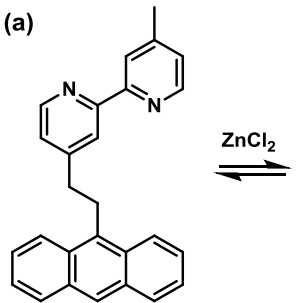

1, high $\phi$

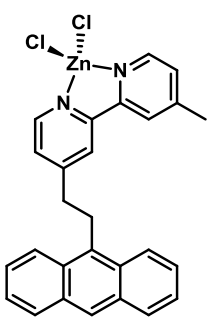

$\left[\mathrm{Zn}(1) \mathrm{Cl}_{2}\right]$, low $\phi$ (b)

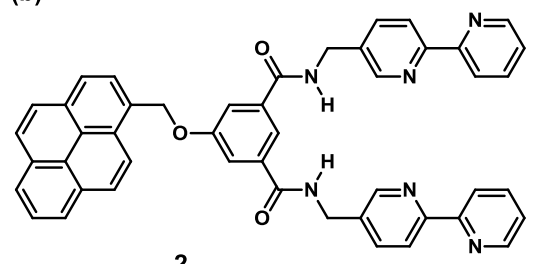

2

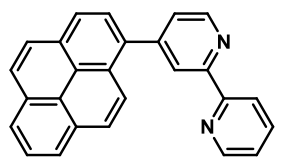

3

Figure 2. (a) Zinc(II) coordination quenches the emission of compound 1 through photoinduced electron transfer (PET) from the excited anthryl to zinc(II)-bound bipy [40]. $\phi$ : fluorescence quantum yield. (b) Similarly, zinc(II) coordination also decreases the fluorescence quantum yields of compounds $\mathbf{2}$ and $\mathbf{3}$ [41, 42].

\section{(2) Zinc(II)-dependent emission of bipy-appended fluorophores - early reports}

In this section, a few studies on bipy-containing fluorescent compounds that inspired our own work are described. Compound $\mathbf{1}$ (Figure 2a), which was reported by de Silva and coworkers, in the metal-free form exhibits anthracene fluorescence [40]. When zinc(II) coordinates the bipy moiety, the LUMO level of bipy drops to the extent that electron transfer from the excited anthryl group to bipy is feasible and rapid. This electron transfer process, sometimes called donor-excited photoinduced electron transfer (d-PeT) because the excited fluorophore is the electron donor [43], quenches the anthryl emission in the solvents that were applied in this study 
[40]. Fages and coworkers reported bipy-containing compounds 2 [41] and 3 [42] (Figure 2b); the pyrene emission of both compounds is similarly diminished upon zinc(II) binding.

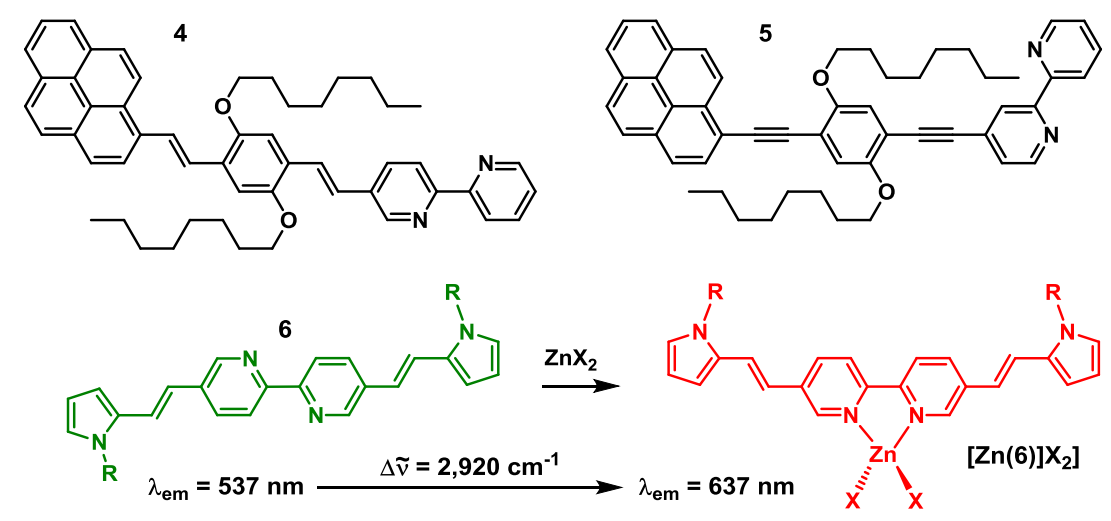

Figure 3. Structures of compounds 4-6, and the emission color change of 6 upon zinc(II) binding in acetonitrile [44].

Fages and coworkers also reported compounds $\mathbf{4}$ and 5 (Figure 3), in which the bipy moieties are conjugated with pyrene fluorophore via $\pi$ bridges [45]. The emission of both compounds exhibits bathochromic shifts, but undiminished emission quantum yields upon binding $\mathrm{ZnCl}_{2}$ in THF and toluene. Similar observations were made in selective organic solvents by Wasielewski, Schmehl, and their coworkers, on bipy-included conjugate polymer [46] and arylvinylterpy ligands [47], respectively. Ajayaghosh and coworkers reported compound 6 (Figure 3), the fluorescence of which turns from green/yellow to orange/red upon zinc(II) complex formation in acetonitrile [44]. Highly fluorescent analogues of $\mathbf{6}$ have since been reported to also have zinc(II)-sensitive fluorescence properties [48-52]. Similar to 4, the bipy moiety in 6 is in conjugation with $N$-methylpyrrole caps via vinyl bridges. The free ligand has a fluorescence quantum yield $(\phi)$ of $\sim 0.4$ in acetonitrile. The $\phi$ value of the zinc(II) complex was not reported. 
Nonetheless, the striking zinc(II)-effected color change of emission drew us to investigate the photophysical mechanism of the zinc(II)-dependent emission of similar compounds, and to find ways to incorporate arylvinylbipy (AVB) moiety in fluorescent indicators for zinc(II) ions that do not undergo fluorescence quenching upon zinc(II) binding.

\section{(3) Arylvinylbipyridines (AVBs) - solvent effect on spectral shape and frequency}

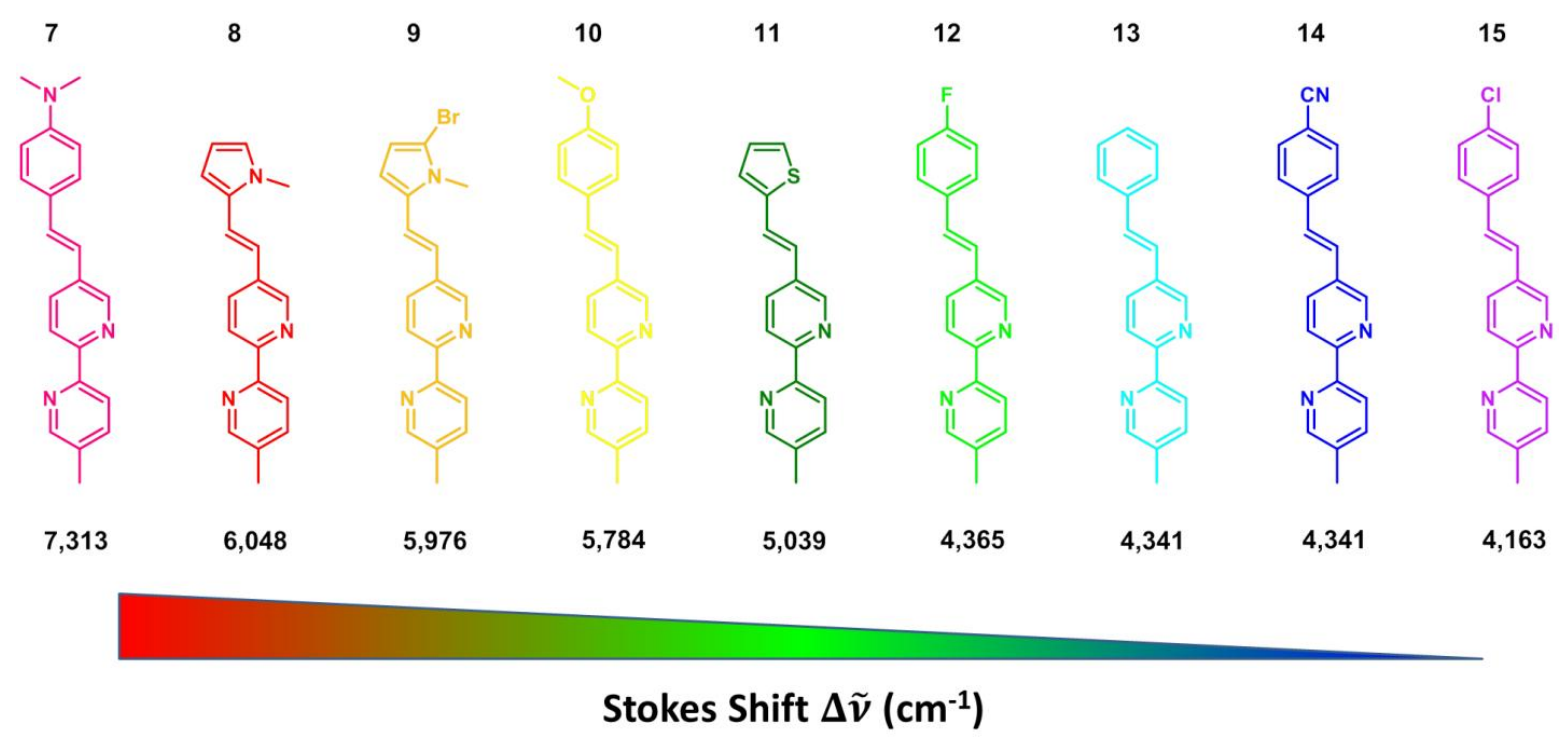

Figure 4. The Stokes shift (listed below the structures in $\mathrm{cm}^{-1}$ ) of AVB measured in acetonitrile decreases (from left to right) as the aryl group becomes more electron-withdrawing [53].

A series of 5-arylvinyl-substituted bipy ligands (7-15) were prepared in our laboratory [53]. Most of these compounds have intermediate to large fluorescence quantum yields $(\phi>0.2)$ and short lifetimes $(\tau<2$ ns) in the vast majority of the tested organic solvents. Depending on the aryl group and the solvent, the emission color of these compounds spans from purple (e.g., $\mathbf{1 4}$ in hexanes) to green/yellow (e.g., 7 in acetonitrile). A positive correlation between the electron donor strength of the aryl ring and emission wavelength as well as the Stokes shift in acetonitrile 
is apparent (Figure 4). This trend is expected for eDonor- $\pi$ Bridge-eAcceptor (D- $\pi$-A, interchangeable with "push-pull") type dyes, in which enhancing either the donor (arylvinyl) or the acceptor (bipy) strength increases the charge transfer character of the excited state (as measured by the excited state dipole moment). The enlarged excited state dipole leads to substantial stabilization in a polar solvent such as acetonitrile, hence a large Stokes shift [54].

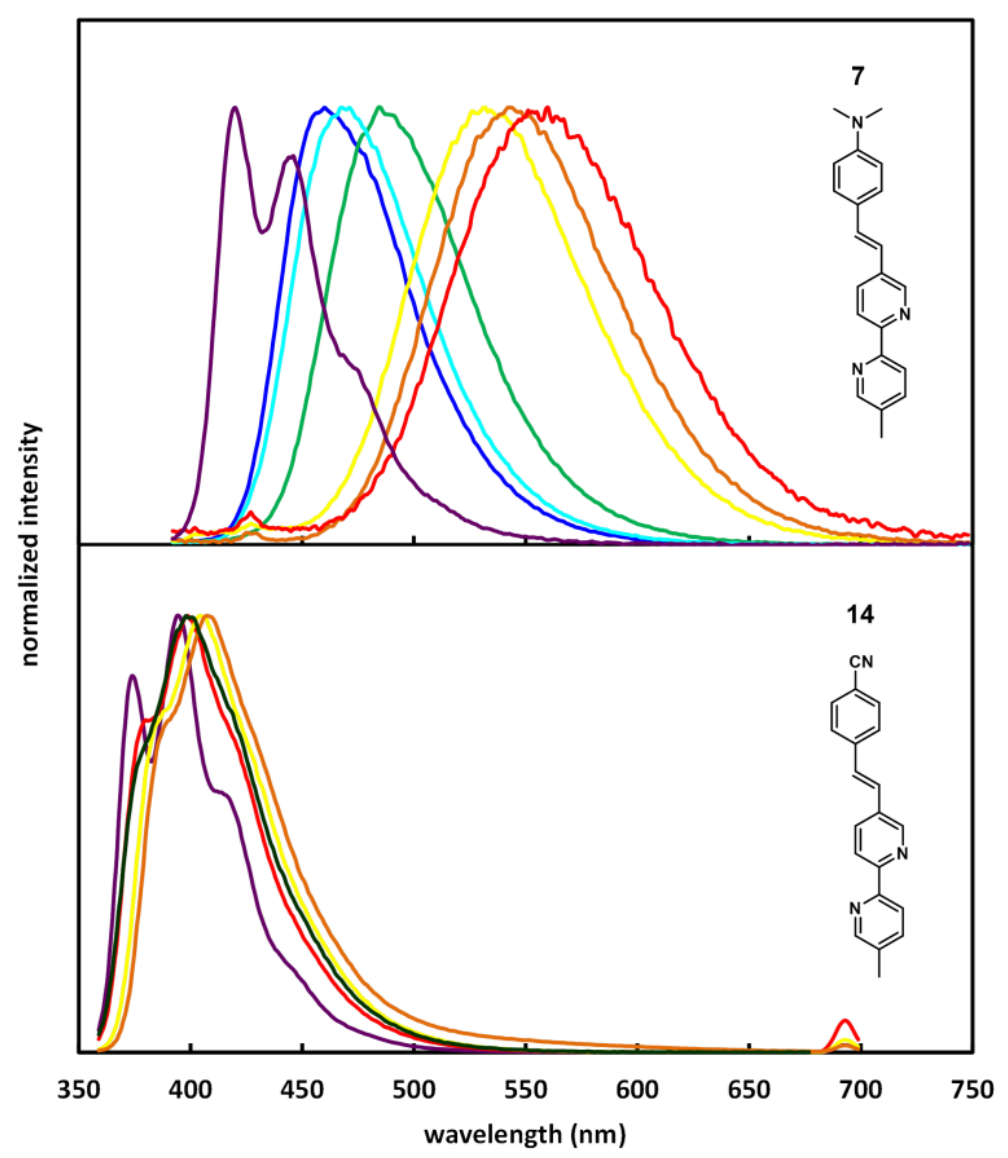

Figure 5. Normalized fluorescence spectra of $\mathbf{7}$ (upper) and $\mathbf{1 4}$ (lower) in different solvents. Methylcyclohexane (7)/hexanes (14): purple; benzene: blue; dioxane: cyan; chloroform: green; acetonitrile: dark green; DMF: yellow; DMSO: orange; methanol: red. The samples were excited at the maxima of their respective absorption spectra. Adapted with permission from Ref. \#53. Copyright (2009) American Chemical Society. 
Solvent effect on emission often reveals important aspects of structure and dynamics of excited fluorophores [54-57]. The normalized emission spectra of $\mathbf{7}$ and $\mathbf{1 4}$ are shown in Figure 5. Compound 7 contains an electron-rich $N, N$-dimethylamino substituent, which leads to a sensitive positive solvatochromic emission shift. The emission of the electron-poor cyano-bearing compound 14, on the other hand, experiences a small solvent effect. Vestiges of vibronic structure are apparent in the spectra of $\mathbf{1 4}$ in all five solvents, while the emission of $\mathbf{7}$ in relatively polar solvents is broad and structureless. The latter is a result of significant inhomogeneous spectral broadening, which is usually caused by the thermal disorder of solvent molecules that strongly interact with a large excited state dipole $[55,58]$.

The emission of compound $\mathbf{1 4}$ may be considered as from a "locally excited" (LE) state of a small dipole moment, because it carries a vibronic structure and little solvent dependence. The structured emission of compound 7 in methylcyclohexane can also be referred as the LE emission by analogy. The structureless, low energy emission of 7 in highly polar solvents, therefore, can be regarded as from a "charge transfer" (CT) excited state. In order to explain the solvent polarity-dependent transition of LE to $\mathrm{CT}$ emission of 7 , we shall first clarify the physical meanings of the terms "LE" and "CT" in the context of excited state solvation.

As opposed to "charge transfer" (CT), "locally excited" (LE) shall literally refer to the excited state resulting directly from the excitation of either the e-donor or the e-acceptor ground state. Therefore, "LE" carries a clear physical meaning in the model of exciplex formation, in which either donor or acceptor is excited to their respective excited states before the exciplex (i.e., the CT excited) state forms. Over time, the use of "LE" (sometimes also referred as the $\pi$ - $\pi$ * state) and "CT" (also known as internal charge transfer (ICT) or intraligand charge transfer (ILCT)) has been extended to describe electronically excited species under many different circumstances, 
including cases in which donor and acceptor are electronically conjugated in the ground state, and their physical meanings have become ambiguous [59-63]. Herein, we make an attempt to define the LE and CT emission (assuming that we will continue to use these terms in the future) of D- $\pi$-A fluorophores similar to AVB compounds in Figure 4.

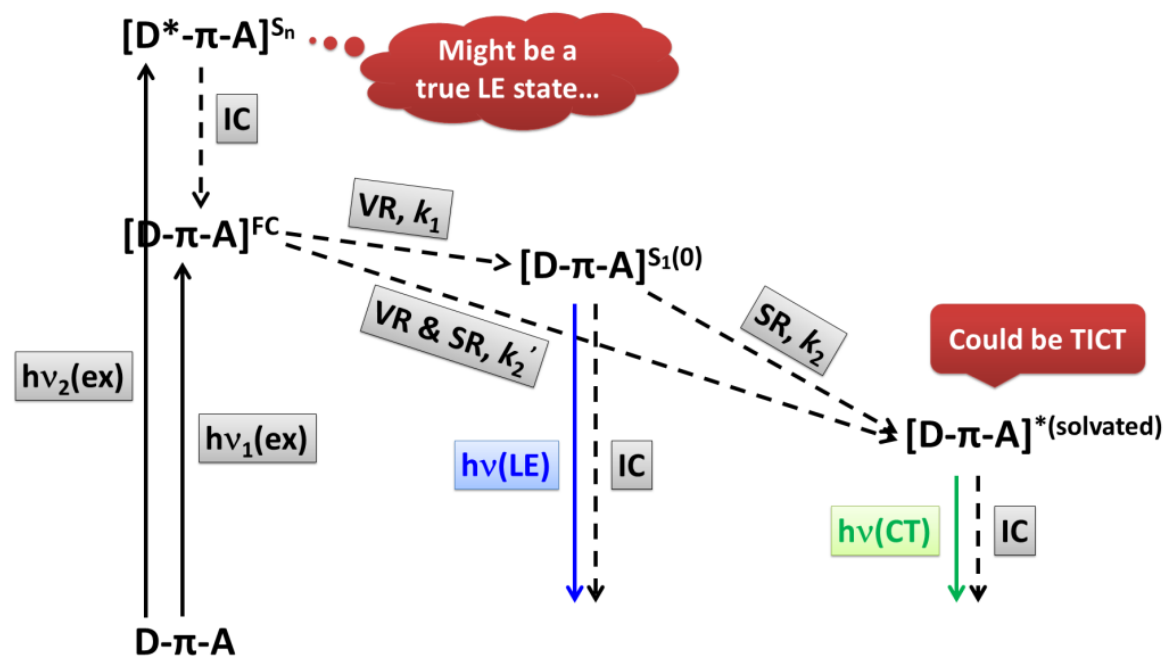

Figure 6. A solvation model for "eDonor- $\pi$ Bridge-eAcceptor" (D- $\pi$-A) fluorophores. ex = excitation; $\mathrm{IC}=$ internal conversion; $\mathrm{VR}=$ vibrational relaxation; $\mathrm{SR}=$ solvent relaxation; $\mathrm{LE}=$ locally excited; $\mathrm{CT}=$ charge transfer; $\mathrm{TICT}=$ twisted intramolecular charge transfer; $k_{1}, k_{2}$, and $k_{2}$ ' are the rates of respective processes.

As shown in Figure 6, a D- $\pi$-A (or “push-pull") molecule, such as 7, is vertically excited to the Franck-Condon $S_{1}$ state $[D-\pi-A]^{\mathrm{FC}}$, or a higher electronic state $S_{n}$, which could be a true "LE" state if the electronic perturbation is localized in the donor portion. The relaxation follows rapidly via vibrational relaxation (VR), or initially via internal conversion (IC) if from $S_{n}(n>1)$, to the ground vibrational state of the first excited state $-S_{1}(0)$ [64]. The VR step of a molecular 
fluorophore takes place regardless of solvation, which results in the Stokes shift between emission and excitation [65]. The magnitude of Stokes shift increases as the vibrational quantum number difference between ground and the Franck-Condon state (a function of nuclear displacement between the excited and ground states) grows. In the absence of strong solvation, if the ground and excited states share similar spacing of vibrational energy levels as most small organic fluorophores do, a mirror-image relationship between the $S_{1}(0)$ emission and excitation spectra is expected. That should be the case for compound 7 in methylcyclohexane (Figure 5a, purple) and compound $\mathbf{1 4}$ in all solvents (Figure 5b), of which the structured low-wavelength band is referred in this article as the LE emission. Hence, the so-called LE emission originates from the $S_{1}(0)$ state without significant solvation, regardless whether the relevant FMOs are restricted within the donor (i.e., the true "local") portion of the molecule, or extended beyond it.

When a D- $\pi$-A molecule such as 7 is excited in a polar solvent, solvent relaxation (SR, Figure 6), which would involve the reorientation of solvent dipoles around the large excited state dipole of the solute, will occur to make things complicated. First, the emission band of the solventrelaxed state is often broad with no vibronic structure (Figure 5a, except purple). This "inhomogeneous spectral broadening" is the result of the thermal disorder of the reoriented polar solvent molecules around polar excited solute molecules. Often times the broad band of a D- $\pi-\mathrm{A}$ fluorophore observed in a polar solvent is referred as the charge transfer (CT) emission from a CT excited state, even if the excited state dipole moment is not necessarily much larger than the excited state formed in the low polarity solvent that displays a structured "LE" emission.

The second complication is in the kinetic profiles from the Franck-Condon to the solvated states. If SR is slower than VR ( $k_{2}<k_{1}$, Figure 6$), \mathrm{S}_{1}(0)$ could be populated. The other possibility is that $\mathrm{SR}$ is on the same time scale with or faster than VR $\left(k_{2} \geq k_{1}\right)$, especially when the 
vibrational energy of the Franck-Condon state is so high due to the large nuclear displacement between excited and ground states, that the large amount of dissipated energy drives (i.e., accelerates) solvent reorientation. In that case, $\mathrm{SR}$ might bypass $\mathrm{S}_{1}(0)$ so that the Franck-Condon excited state relaxes directly to a solvated state $[\mathrm{D}-\pi-\mathrm{A}]^{*_{\text {solvated }}}$ with rate $k_{2}$ '. The solvent relaxation process of compound $\mathbf{1 0}$ (Figure 4) in acetonitrile was captured by femtosecond timeresolved transient absorption spectroscopy with a time constant of 53 ps [66], which is shortened as the solvent polarity grows. Regardless how the solvated state is reached from the FranckCondon state, as long as the excited dipole moment remains unchanged during solvation (i.e., solute polarizability can be neglected) and no specific solvent-solute interaction (e.g., hydrogen bonding) is involved, the Lippert-Mataga equation based on a thermodynamic model could predict the change of Stokes shift as a function of solvent polarity to a moderate accuracy [54, $56,67-69]$. The slope of this linear equation is the change of molecular dipole of the fluorophore upon photo-excitation. In the former case $\left(k_{2}<k_{1}\right)$ in which $\mathrm{S}_{1}(0)$ is a local minimum on the excited state potential energy surface, dual emission from the LE and CT states might be observed (more on this later).

If a specific solvent-solute interaction (e.g., solvent forms hydrogen-bonds with the excited state dipole) influences the energy of the excited state, and/or the excited state dipole changes as the solvent relaxation proceeds, a poor fit to the Lippert-Mataga equation is to be expected [70]. This is the case for compound 7 [48], because its emission energy is at the lowest in methanol, which has the largest hydrogen bond acidity, not DMSO, which has the largest dielectric constant. In many cases, solvation might lead to an increase of the excited state dipole and even conformational changes if the lifetime of the excited state is long enough. The extreme scenario 
would be the formation of the "twisted intramolecular charge transfer" (TICT) state [59, 71], which has been extensively studied as a model of dual emission ("LE" $v s$ "CT").

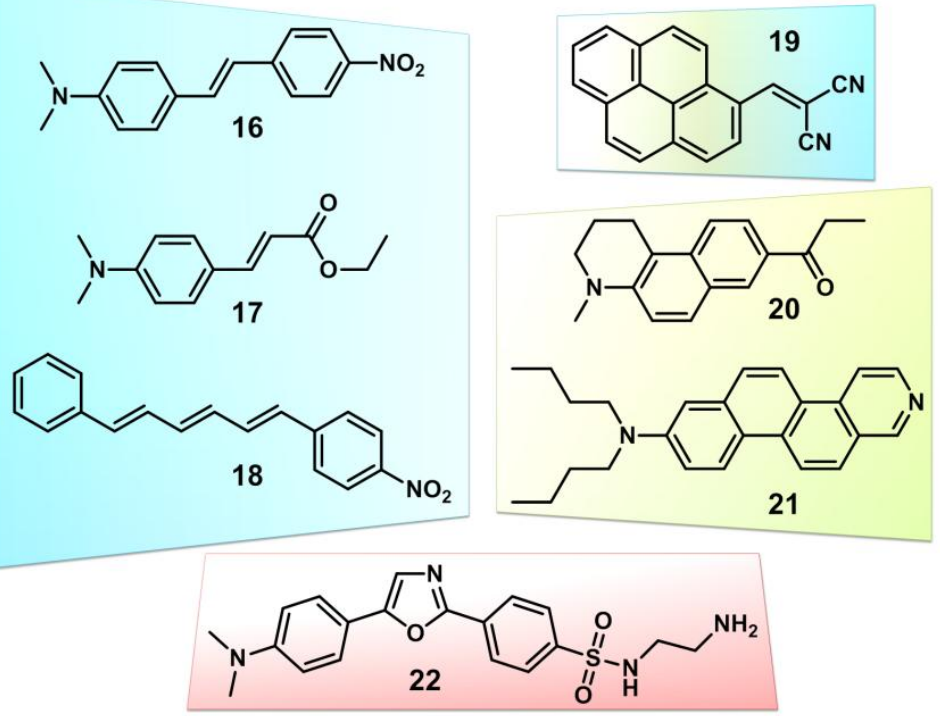

Figure 7. Examples of D- $\pi$-A (push-pull) dyes similar to AVBs. Different colors represent different $\pi$ bridges: blue - (poly)vinyl bridges in compounds 16 [54], 17 [72], and 18 [73]; yellow: fused aromatics in $\mathbf{2 0}$ [74] and $\mathbf{2 1}$ [62]; yellow and blue: both fused aromatic and vinyl in 19 [75]; red: single ring aromatics in 22 [76].

Based on the above discussions, we hereby define the LE and CT states of AVB fluorophores. An LE state is the vibrationally relaxed first excited state $\left(\mathrm{S}_{1}(0)\right)$ without significant solvation, regardless of the magnitude of the excited state dipole moment. The LE emission band shall exhibit a vibronic structure and mirror-image relationship with its excitation spectrum. A CT state is the solvated excited state with a large dipole moment in a polar solvent, which affords a broad, structureless emission band of a lower energy than its $\mathrm{S}_{1}(0)$ state. Based on this definition, 
an LE state could be achieved by any fluorophore, regardless of the size of its excited state dipole, in an environment lacking a strong solvent-solute interaction (i.e., either solvent or solute dipole is small, or both). A CT state requires both a large excited state dipole and a polar solvent. Compound 14 therefore exhibits LE emission in all solvents, because its excited state dipole moment is not large enough to drive significant solvent reorientation. For compound 7, an LE state is assigned to the emission in methylcyclohexane, while in more polar solvents the emission is assigned to a CT state. Many reported push-pull dyes exhibit similar "LE" $\rightarrow$ "CT" emission spectral evolution in shape and frequency as the solvent polarity increases. Examples 16-22 are shown in Figure 7 that are grouped based on the structures of $\pi$-bridges.

\section{(4) Zinc(II)-dependent emission of AVB in the context of fluorescence imaging}

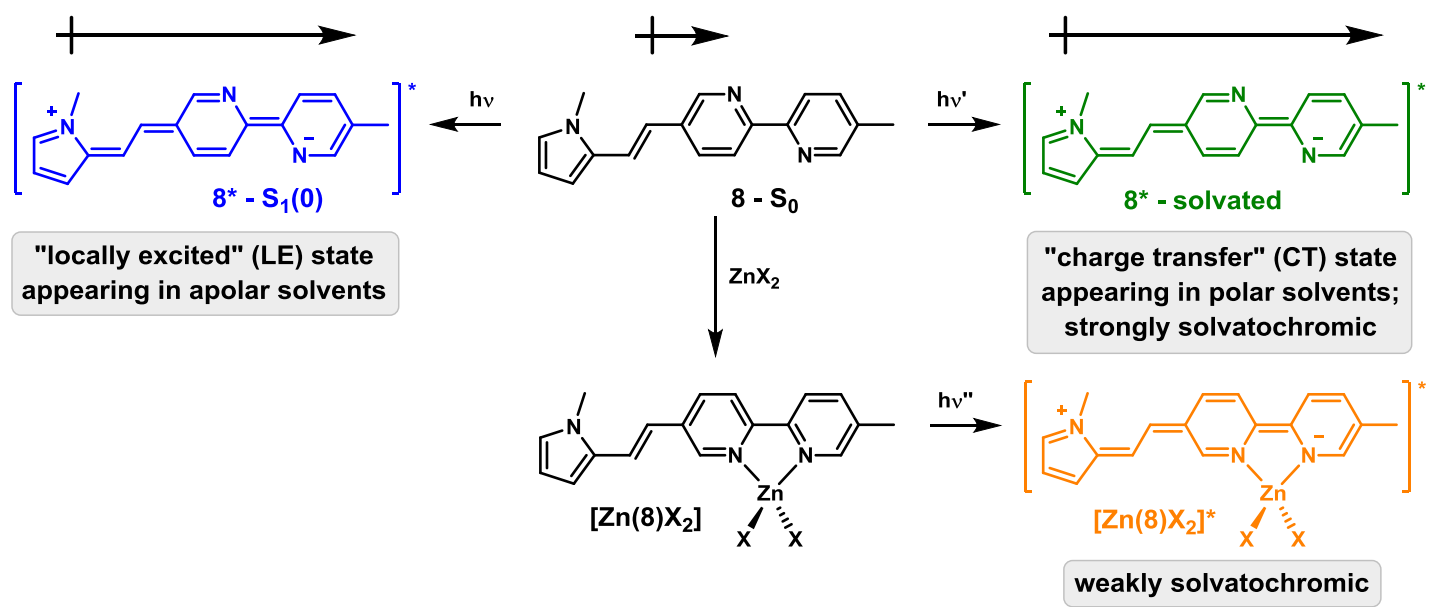

Figure 8. The dependency of the emission of $\mathbf{8}$ on solvent and zinc(II) binding. X: a monodentate counter ion.

Compound 8 carries an electron-rich $N$-methylpyrrole group (Figure 8) [53]. Upon photoexcitation, an increase in molecular dipole moment is expected regardless of solvent, during 
which the electron density shifts from the $N$-methylpyrrole side to the bipy moiety. In the nonpolar solvent hexanes, an emission band of the LE character was observed, while in polar solvents (e.g., acetonitrile) a broad, structureless, and solvent-sensitive CT band appeared. When zinc(II) coordinates at the bipy position, the cationic zinc(II) interacts with the negative end of the excited state dipole to strongly stabilize the excited state. Therefore, a large zinc(II)-enabled spectral shift results $\left(4,277 \mathrm{~cm}^{-1}\right.$ in acetonitrile), which is somewhat insensitive to solvent polarity, because the strong interaction between the cationic zinc(II) and the dipolar excited state largely overrides the solvent effect.

(a)
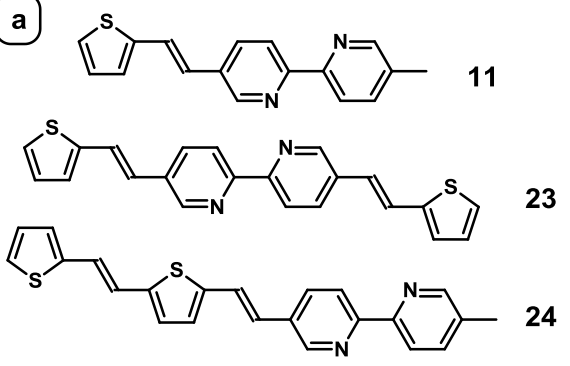

(b)

\begin{tabular}{l|ccc} 
& $\lambda_{\mathrm{L}} / \mathrm{nm}$ & $\lambda_{\mathrm{ZnL}} / \mathrm{nm}$ & $\Delta \lambda / \mathrm{nm}\left(\tilde{v} / \mathrm{cm}^{-1}\right)$ \\
\hline 11 & 422 & 504 & $82(3,855)$ \\
23 & 458 & 527 & $69(2,859)$ \\
24 & 497 & 622 & $125(4,044)$
\end{tabular}

Figure 9. (a) The structures of compounds 11, 23, and 24, and (b) the emission maxima of the compounds and their zinc(II) complexes, and the zinc(II)-effected emission shifts.

Ajayaghosh and coworkers postulated that zinc(II) coordination planarizes the bipy-containing ligand 6 (Figure 3), which results in a larger aromatic system with a lower HOMO-LUMO gap, and consequently leads to a bathochromic shift in emission [44]. However, considering the fact that unlike biphenyl, the transoid co-planar conformation of 2,2'-bipyridine [77] is the most stable in the ground state [78], the stabilization of the polarized excited state via metal coordination could be a more dominant factor in contributing to the emission bathochromic shift 
than forcing co-planarity. To gauge the relative contributions of fluorophore planarization and excited state dipole stabilization to the zinc(II) coordination-effected emission bathochromic shifts in AVBs, the emission data of compounds 11, 23, and 24 are compared (Figure 9).

Zinc(II) binding results in an emission shift of $3,855 \mathrm{~cm}^{-1}$ for $\mathbf{1 1}$ in acetonitrile [53]. If fluorophore planarization is the dominant factor leading to the bathochromic shift, compound $\mathbf{2 3}$, which would have provided a bigger planar conjugated system upon zinc(II) complexation, should have given a larger zinc(II)-induced shift under the same conditions. To the contrary, zinc(II)-coordination of $\mathbf{2 3}$ affords a smaller shift of $2,859 \mathrm{~cm}^{-1}$. When both thienylvinyl groups locate on the same side of bipy, as in $\mathbf{2 4}$, the largest shift of $4,044 \mathrm{~cm}^{-1}$ upon zinc(II) binding was observed [79]. The comparison of zinc(II)-effected emission shifts of these three compounds points to the stabilization of the excited state dipoles (or the CT excited states) as the major factor in determining the magnitude of the shifts. Phen-containing fluorophores, which have rigid planar conformations to begin with, also undergo substantial emission bathochromic shifts when binding zinc(II) in organic solvents [80], attributable to the stabilization of CT excited states.

$$
\begin{array}{ll}
\tau=\frac{1}{k_{r}+k_{n r}} & \text { Equation 1 } \\
\phi=\frac{k_{r}}{k_{r}+k_{n r}} & \text { Equation 2 }
\end{array}
$$

Zinc(II) complexation increases the fluorescence lifetimes $(\tau)$ of compounds 8-15 in acetonitrile (zinc(II) completely quenches the emission of 7) [48]. The fluorescence quantum yields $(\phi)$ of the zinc(II)-bound 8-15 are also larger than those of the metal-free forms, although to lesser extents comparing to the changes in $\tau$. Similar zinc(II)-dependent effect on $\tau$ and $\phi$ of bipy-containing conjugate polymers was also observed by Chen, Wasielewski, and coworkers [46]. The rates of radiative $\left(k_{\mathrm{r}}\right)$ and nonradiative $\left(k_{\mathrm{nr}}\right)$ decays were calculated from Equations 1 and 2. Both rates for 8-15 decrease upon zinc(II) coordination. Because zinc(II) coordination of 
the ligands enhances the $\mathrm{CT}$ character of the excited state, the diminishing orbital overlap between the excited and ground states shall reduce the rate of radiative decay $\left(k_{\mathrm{r}}\right)$. This argument has been used to explain the low fluorescence quantum yields of exciplexes [81] and TICT [71] excited states, two limiting cases with complete excited state charge transfer. The rate of nonradiative decay $\left(k_{\mathrm{nr}}\right)$ of an AVB also decreases upon zinc(II) coordination [53]. This observation is not wholly expected because it runs counter to the energy gap law $[82,83]$, which predicts an increase in $k_{\mathrm{nr}}$ when the emission frequency drops upon zinc(II) binding. Likely the restriction of the single bond rotation in the zinc(II)-bound bipy moiety reduces the probability of nonradiative decay. Therefore, the $\tau$ value increases because both $k_{\mathrm{r}}$ and $k_{\mathrm{nr}}$ decrease upon zinc(II) binding (Equation 1), while the $\phi$ value of the ligand (Equation 2) is spared from the quenching effect of a substantially $\mathrm{CT}$ excited state of the zinc(II)-bound complex by a lowered $k_{\mathrm{nr}}$.

Compound $\mathbf{1 0}$ is an example of AVBs that could be used in fluorescence imaging of intracellular zinc(II) ions [84]. Zinc(II) complex formation raises the $\phi$ of $\mathbf{1 0}$ in an neutral aqueous solution from 0.05 to 0.31 with an emission maximum at $513 \mathrm{~nm}$. The dissociation constant of $[\mathrm{Zn}(\mathbf{1 0})]^{2+}$ was estimated at $\sim 1 \mu \mathrm{M}$ using a 1:1 binding model. Bipy-derived compounds selectively bind transition metal ions of intermediate hardness over alkali and alkaline earth metal ions such as sodium(I) or magnesium(II). The selectivity of $\mathbf{1 0}$ for transition metal ions follows the Irving-Williams order and hard/soft acids and bases (HSAB) theory, which means that bipy does not show a particular affinity to zinc(II) over other transition metal ions. Nonetheless, the bipy moiety is considered to have adequate selectivity in biological settings, in which the major interference would have come from sodium(I), potassium(I), magnesium(II), and calcium(II). Compound $\mathbf{1 0}$ was taken up by mammalian cells readily upon incubation at a low concentration $(\sim 2 \mu \mathrm{M})$. It did not exhibit any sign of cytotoxicity over the 
course of the experiment [85]. Therefore, the brightness, zinc(II) sensitivity, selectivity, and uptake/toxicity of $\mathbf{1 0}$ are all suitable as an indicator for biological zinc(II) in a matching concentration range. One major weakness of bipy as a receptor for zinc(II) is the uncertainty in binding stoichiometry in differently buffered environments. Bipy is known to form $\mathrm{ZnL}, \mathrm{ZnL}_{2}$, and $\mathrm{ZnL}_{3}$ complexes [86], depending on counter ion and solvent. The variability of the binding stoichiometry complicates quantitative analysis of zinc(II).
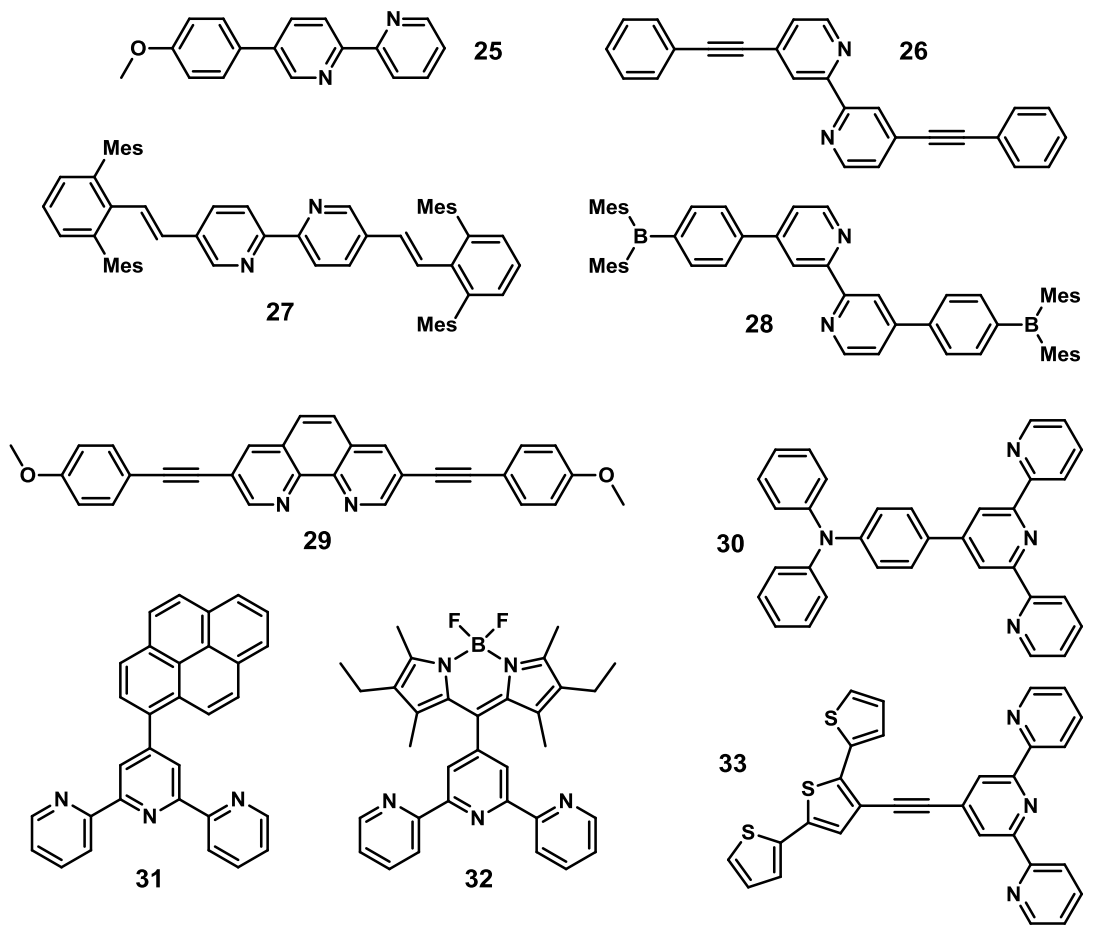

Figure 10. Selected fluorescent ligands containing bipy or its analogues: 25 [87], 26 [88], 27 [89], 28 [90], 29 [80], $\mathbf{3 0}$ [91], $\mathbf{3 1}$ [92], $\mathbf{3 2}$ [93], and $\mathbf{3 3}$ [94].

Selected bipy- or bipy analogue-containing, zinc(II) sensitive-fluorophores 25-33 are shown in Figure 10. Considering bipy as an electron acceptor, the zinc(II)-dependent fluorescence bathochromic shifts of 25-27 can also be explained using the D- $\pi$-A model [95] that is applied to 
compound 8 (Figure 8). Similar to that of $\mathbf{2 5}$, the zinc(II)-sensitive emission of 4-methoxy-2,6dimethylphenyl-substituted bipy ligands was reported by Loren and Siegel [96]. Four bulky mesityl groups are included in compound $\mathbf{2 7}$, which biases toward a 1:1 binding stoichiometry with zinc(II) [89]. Although compound 28 lacks a D-A type structure, zinc(II) binding nonetheless leads to an emission red shift [90]. More experimental data is needed to establish a photophysical model of $\mathbf{2 8}$ to account for this observation. The zinc(II)-dependent spectral change of phen- (29) and terpy- (30-33) included fluorophores can also be explained using the D- $\pi$-A model. However, for terpy-functionalized fluorophores, fluorescence quenching usually accompanies the bathochromic shift upon zinc(II) coordination. In these cases, a terpy/zinc(II) complex acts as an excellent electron acceptor to possibly lead to the formation of fully charge separated excited states, which tend to decay predominantly via non-radiative processes.

\section{(5) AVBs in fluorescent heteroditopic ligands}

A fluorescent heterotopic ligand has two different metal coordination sites (Figure 11) [97]. When a metal ion encounters the ligand, it associates with the high-affinity binding site (the rectangle in Figure 11) to afford a mononuclear complex. Further increase of the metal ion concentration shall lead to the formation of the dinuclear complex. If these three species - metalfree ligand, mononuclear, and dinuclear complexes - have distinct fluorescence properties as characterized by their emission wavelengths $(\lambda)$ and fluorescence quantum yields $(\phi)$, the fluorescence changes could be correlated to the metal ion fluctuation over a large concentration range. These compounds could be particularly useful as fluorescent indicators for zinc(II), a biologically significant ion that has a broad physiological concentration range $[98,99]$ in its strictly regulated "free" forms [100]. Moreover, studies on the interplay between ligand-centered 
photophysics and zinc(II) coordination chemistry in a heteroditopic architecture are challenging, but on the other hand are rewarded with new insights on the fundamental knowledge on both fronts. In this section, we describe four fluorescent heteroditopic ligands that contain the AVB components. The subsections are titled by the photophysical switches [101] that are turned either "on" or "off" by sequential binding of zinc(II). A brief tutorial on how these switches work and how they are characterized is included in a recent review from our group [102].

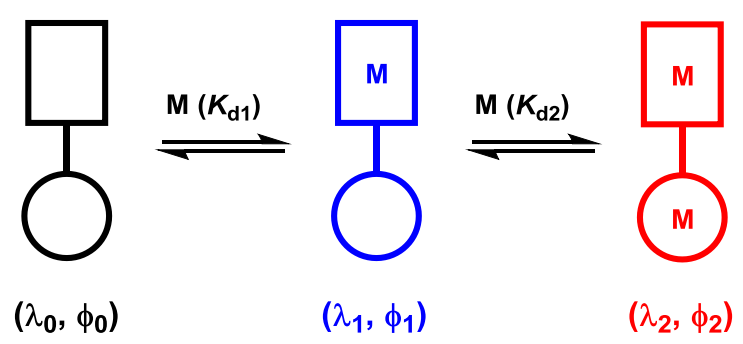

Figure 11. An illustration of a sequential metal coordination process of a fluorescent heteroditopic ligand. Rectangle: high-affinity binding site; circle: low-affinity binding site. $K_{\mathrm{d}}$ : dissociation constant $\left(K_{\mathrm{d} 1}<K_{\mathrm{d} 2}\right)$.

(5a) PET/ICT. Compound 34 contains a di(2-picolyl)amino (DPA) group and a phenylvinylbipy fluorophore (Figure 12a) [103]. In its metal-free form in acetonitrile, $\mathbf{3 4}$ is weakly fluorescent because the excited state fluorophore is quenched via photoinduced electron transfer (PET) from the tertiary amino group on DPA. In this medium, DPA has a higher affinity for zinc(II) than bipy. Therefore, DPA first captures a zinc(II) ion to form the mononuclear $\left(\left[\mathrm{Zn}(\mathbf{3 4}) \mathrm{Cl}_{2}\right]\right.$. The coordinative bond between the tertiary amino and zinc(II) renders the PET less likely to occur, which results in the increase of fluorescence quantum yield. The fluorescence enhancement via turning off a "PET switch" is a widely applied strategy in developing turn-on 
fluorescent indicators [101, 104-106]. The binding of the second zinc(II) ion necessarily occurs at the bipy site, which stabilizes the CT excited state to lead to a bathochromic shift of emission. Therefore, the sequential zinc(II) binding of $\mathbf{3 4}$ leads to two distinct segments of fluorescence changes - fluorescence enhancement $\left(\phi_{1} / \phi_{0}\right)$ followed by emission bathochromic shift $\left(\Delta \lambda=\lambda_{2^{-}}\right.$ $\left.\lambda_{1}\right)$. The extents of these two changes are the benchmarks for evaluating the effectiveness of heteroditopic ligands of the PET/ICT type.

(a)

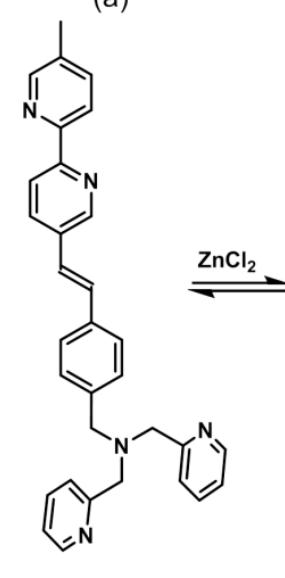

34

$$
\begin{aligned}
\lambda_{0}^{M e C N} & =395 \mathrm{~nm} \\
\phi_{0} & =\mathbf{0 . 0 3}
\end{aligned}
$$

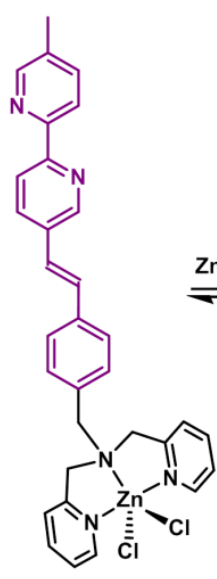

$\left[\mathrm{Zn}(34) \mathrm{Cl}_{2}\right]$

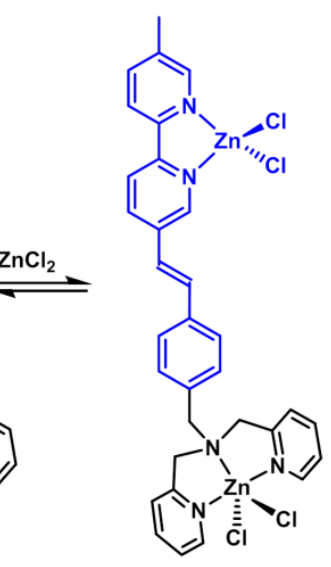

$\left[\mathrm{Zn}_{2}(34) \mathrm{Cl}_{4}\right]$

$\begin{aligned} \lambda_{2}^{M e C N} & =455 \mathrm{~nm} \\ \phi_{2} & =0.63\end{aligned}$ (b)

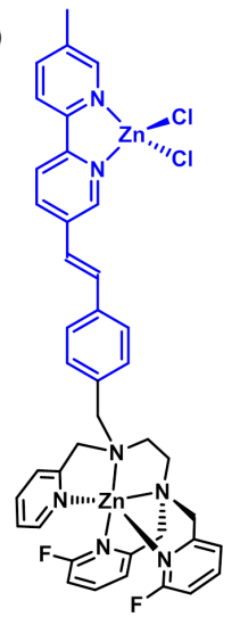

$\left[\mathrm{Zn}_{2}(35) \mathrm{Cl}_{2}\right]^{2+}$

$\lambda_{2}^{\mathrm{H}_{2} \mathrm{O}}-\lambda_{1}^{\mathrm{H}_{2} \mathrm{O}}=28 \mathrm{~nm}$

Figure 12. (a) The sequential binding of zinc(II) of compound 34. $\phi_{1} / \phi_{0}=18, \Delta \lambda=60 \mathrm{~nm}$ in acetonitrile; (b) the dinuclear zinc(II) complex of compound 35. $\phi_{1} / \phi_{0}=5.4, \Delta \lambda=28 \mathrm{~nm}$ in an aqueous solution at neutral $\mathrm{pH}$.

In order for a heteroditopic ligand to be useful as a fluorescent indicator for illuminating biological zinc(II) ions, the zinc(II) coordination-modulated fluorescence changes need to be 
replicated under physiological conditions. It is not the case for compound $\mathbf{3 4}$ because the affinities of DPA and bipy are too close at neutral $\mathrm{pH}$ in water for a discrete mononuclear complex to populate. To rectify this situation, the tridentate DPA is replaced by a pentadentate ligand that contains two fluorinated pyridyl groups in compound 35 (Figure 12b) [107]. A clearcut two-segment fluorescence change of $\mathbf{3 5}$ was observed in an aqueous solution buffered at neutrality. The monozinc(II) complexation leads to a 5.4-fold amplification of $\phi$, while the secondary binding at bipy results in an emission shift of $28 \mathrm{~nm}$.

The 28-nm zinc(II)-dependent emission band separation of $\mathbf{3 5}$ jeopardizes the potential utility of fluorescent heteroditopic ligands in fluorescence microscopy [108], while the two emission bands need to be resolved using different filter sets. It is noted that in acetonitrile, the zinc(II)induced shift of compound 34 reaches $60 \mathrm{~nm}$ [103]. The dependence of zinc(II)-induced emission shift on solvent is a consequence of the differing solvatochromic effects of the metalfree and zinc(II)-bound forms. A metal-free push-pull AVB has a much larger degree of positive emission solvatochromism than its zinc(II) complex (e.g., see compound $\mathbf{8}$ in Figure 8). Therefore, as the solvent polarity increases when going from acetonitrile to water, the free ligand emission moves to the red while that of the zinc(II) complex barely changes. Consequently, the emission gap between zinc(II)-free and-bound forms is shrinking.

The small emission band separation between zinc(II)-free and -bound forms in water (or highly polar solvents) of an AVB ligand is the manifestation of the inherent property of a push-pull fluoroionophore. To improve the emission shift $(\Delta \lambda)$, which is a benchmark for evaluating fluorescent heteroditopic ligands, a molecular design that utilizes entirely different zinc(II)modulated photophysical processes is called upon, which is represented in $\mathbf{3 6}$ (Figure 13). 


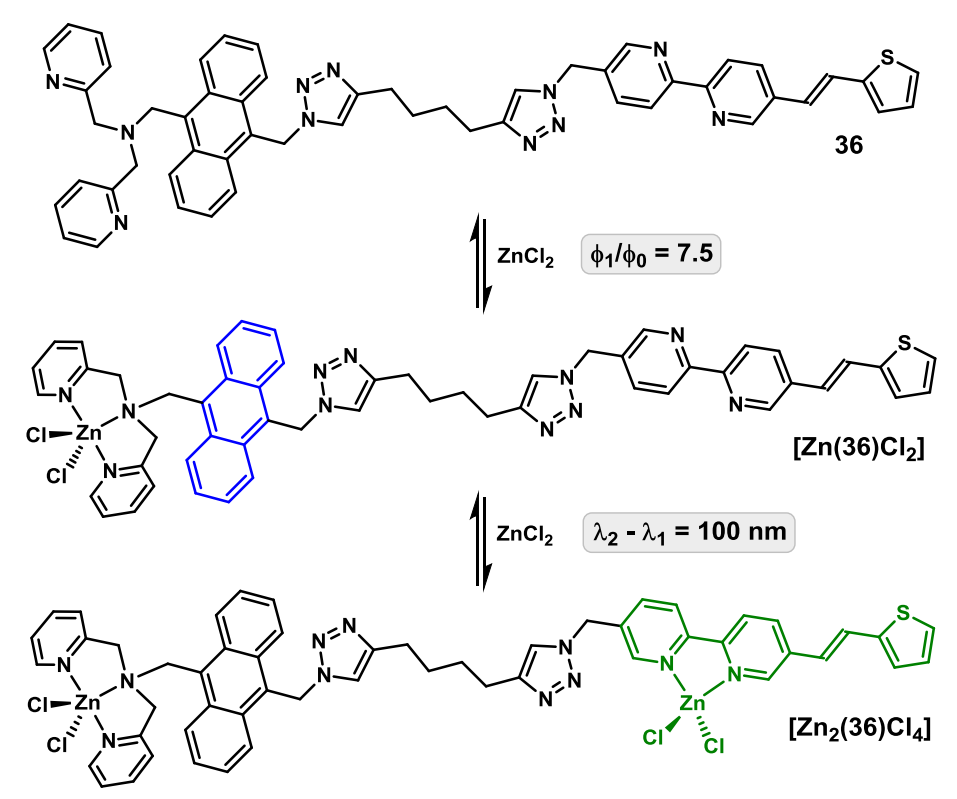

Figure 13. Sequential zinc(II) binding of compound 36, and corresponding fluorescence change. $\phi_{1} / \phi_{0}=7.5 ; \Delta \lambda=100 \mathrm{~nm}$ in acetonitrile.

(5b) PET/ICT/FRET. Compound 36 contains two fluorophores [109]. The higher energy fluorophore anthryl is not solvatochromic. It is connected to a PET-switching DPA unit, which quenches the anthryl emission in the metal-free form. Thienylvinylbipy is the second fluorophore that also contains the secondary (lower-affinity) binding site bipy. The photo-excitation of the anthryl group only leads to a weak emission of the metal-free $\mathbf{3 6}$ because the excited anthryl nonradiatively relaxes via the PET pathway. Zinc(II) acts on the PET switch in the mononuclear complex to restore the anthryl emission. The following bipy/zinc(II) complexation leads to an absorption bathochromic shift of the thienylvinylbipy fluorophore, which increases the spectral overlap with the anthryl emission. Consequently, Förster resonance energy transfer (FRET) occurs to result in the emission of the zinc(II)-bound thienylvinylbipy. Both anthryl and zinc(II)bound thienylvinylbipy are weakly solvatochromic. Therefore, comparing to $\mathbf{3 4}$ and $\mathbf{3 5}$ that 
contain single D- $\pi$-A type fluorophores, the solvent effect on the emission of $\mathbf{3 6}$ is reduced. The two emission bands of $\mathbf{3 6}$ and its dizinc(II) complex, as characterized in acetonitrile [109], are $100 \mathrm{~nm}$ apart and are not expected to be solvent sensitive. Therefore, in principle, the two segments of emission changes could be monitored using blue and green emission filter sets.

(a)
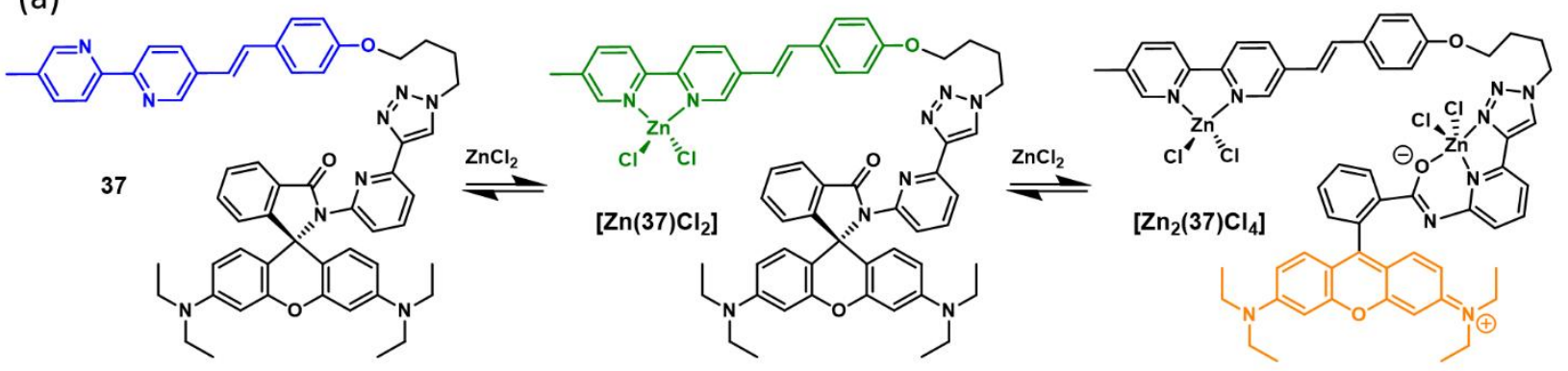

(b)

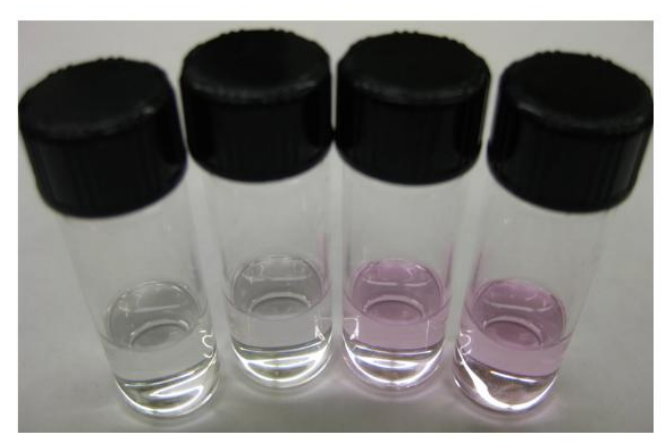

(c)

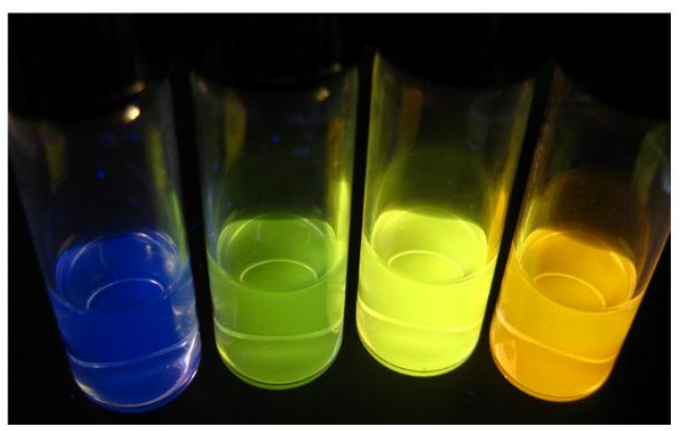

Figure 14. (a) Fluorescence changes of compound 37 upon sequential binding of zinc(II) in acetonitrile; (b) the change of color of a solution of $\mathbf{3 7}$ as the concentration of zinc(II) perchlorate increases from left to right; (c) corresponding changes in the color of emission.

(5c) ICT/spiro-rhod/FRET. In addition to fluorescence enhancement $\left(\phi_{1} / \phi_{0}\right)$ followed by emission band shift $\left(\lambda_{2}-\lambda_{1}\right)$ as the two segments of changes of a heteroditopic ligand, zinc(II)dependent sequential emission band shifts $\left(\Delta \lambda_{1}=\lambda_{1}-\lambda_{0} ; \Delta \lambda_{2}=\lambda_{2}-\lambda_{1}\right)$ over a significant portion of 
the visible spectrum would also be a useful outcome. Compound 37 (Figure 14) includes an AVB moiety and a spirolactam precursor of rhodamine [110]. The emission color of the alkoxyphenylvinylbipy fluorophore is blue, which turns to green when zinc(II) binds. After saturating the bipy site, zinc(II) would then occupy the tridentate pocket consisting the carbonyl, pyridyl nitrogen, and triazolyl N3, which leads to the cleavage of the spiro C-N bond and the formation of the fluorescent rhodamine (hence "spiro-rhod" in the section title) [111-114]. FRET from the zinc(II)-bound AVB to rhodamine switches the emission from green to orange.

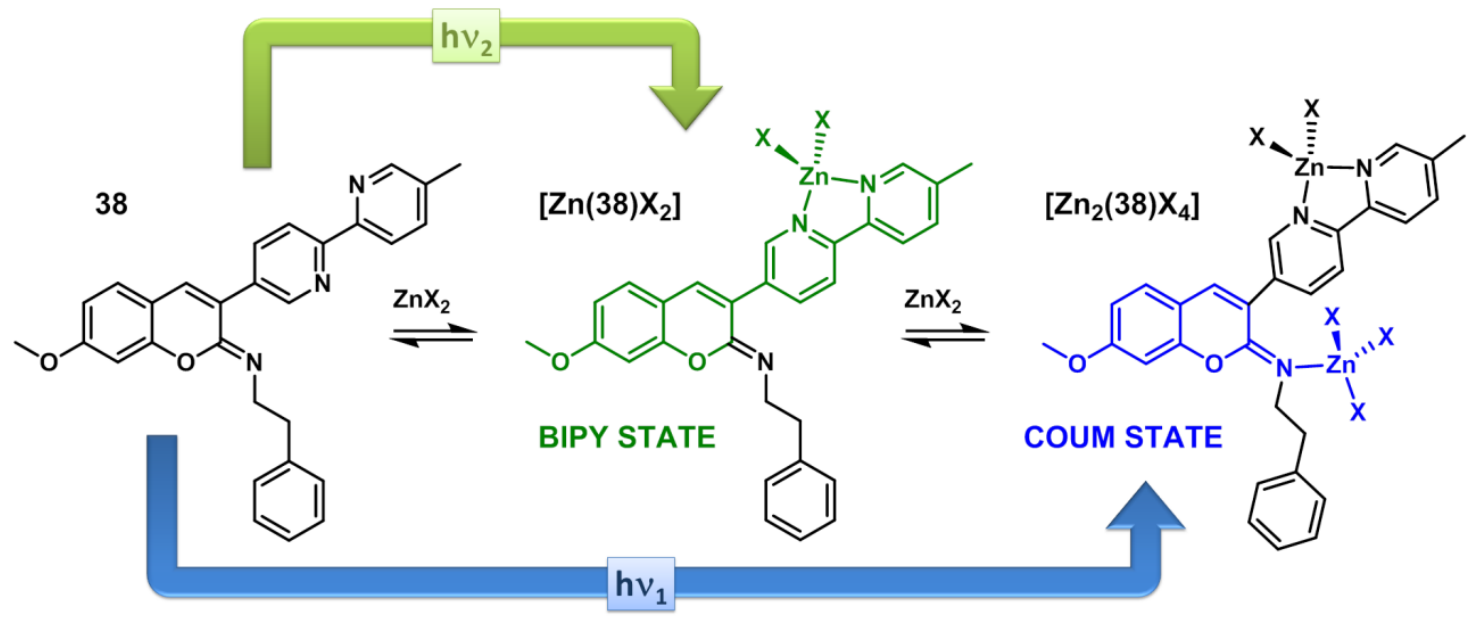

Figure 15. The zinc(II)-dependent dual-emitting iminocoumarin 38. $X=$ monodentate anion.

(5d) ICT1/ICT2. Compound $\mathbf{3 8}$ consists of an iminocoumarin moiety and a bipy substituent [115]. The excitation of $\mathbf{3 8}$ may lead to the formation of two different CT excited states depending on the applied excitation energy. The high-energy excited state primarily involves the iminocoumarin moiety (COUM state in Figure 15), in which the imino nitrogen acts as an electron acceptor while the methoxy is the electron donor. At a lower energy the charge transfer from the methoxy to the bipy moiety could instead become dominant (BIPY state). This 
hypothesis is based on the calculations on the frontier molecular orbital arrangements of $\mathbf{3 8}$, which is consistent with the experimental observations [115]. Either the COUM or the BIPY transitions might be favored in two populations of ground state conformers that differ in the dihedral angle between the coumarin and bipy moieties. After the fluorescence properties of compound $\mathbf{3 8}$ was reported [115], we acquired the single crystal structure of the analogous compound 39 (Figure 16a), which has a dihedral angle (C1-C2-C3-C4) of $45^{\circ}$, close to the $40^{\circ}$ of the most stable conformer predicted from the conformational analysis [115].

(a)
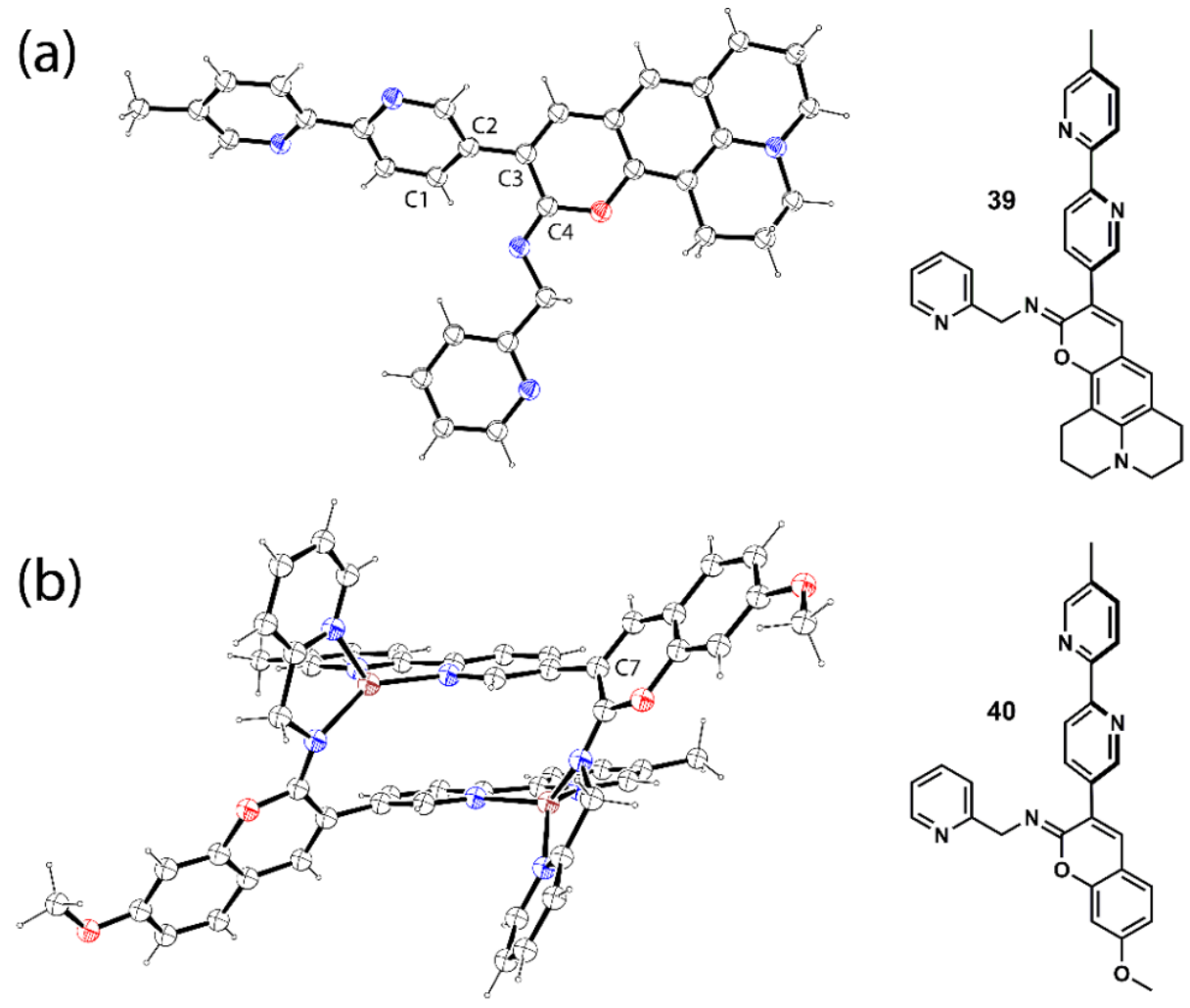

Figure 16. X-ray single crystal structures of compound 39 and complex $\left[\mathrm{Zn}_{2}(\mathbf{4 0})_{2}\right]^{4+}$. Carbon and hydrogen: black; oxygen: red; nitrogen: blue; zinc: brown. 
Both bipy and imino nitrogen in $\mathbf{3 8}$ are able to bind zinc(II), as supported in a crystal structure of the zinc(II) complex of $\mathbf{4 0}$ (Figure 16b), the $N$-(2-picolyl) analogue of $\mathbf{3 8}$ [116]. Without the $N$-(2-picolyl) group in $\mathbf{4 0}$, it is assumed that the bidentate bipy has a higher affinity than the monodentate imino group, as in $\mathbf{3 8}$. Increasing the concentration of zinc(II) perchlorate in the acetonitrile solution of $\mathbf{3 8}$ first elicits an emission band in green color, followed by a hypsochromic shift to blue as zinc(II) concentration continues to rise (Figure 15) [115]. It was concluded that the bipy moiety initially captures a zinc(II) ion to stabilize the lower energy BIPY excited state, which affords the green emission. Further addition of zinc(II) results in the imino/zinc(II) coordination, which stabilizes the higher energy, blue-emitting COUM state. This work opens the door to investigating fluorescent compounds that may exhibit dual emission from two orthogonal charge-transfer states, between which either the internal conversion is slow (a violation of Kasha's Rule), or the ground state conformations differ.

Table 1. Emission wavelength maxima and quantum yields of heteroditopic compounds 34, 36, 37, and 38, monotopic compounds 41 and 42, and their zinc(II) complexes in acetonitrile.

\begin{tabular}{llllllll}
\hline ligand & $\lambda_{0}(\mathrm{~nm})$ & $\lambda_{1}(\mathrm{~nm})$ & $\lambda_{2}(\mathrm{~nm})$ & $\phi_{0}$ & $\phi_{1}$ & $\phi_{2}$ & Ref. \# \\
\hline $\mathbf{3 4}$ & 395 & 395 & 455 & 0.03 & 0.53 & 0.63 & 103 \\
$\mathbf{3 6}$ & 424 & $410 / 428^{\mathrm{a}}$ & 514 & 0.02 & 0.15 & 0.13 & 109 \\
$\mathbf{3 7}$ & 431 & 528 & 587 & N.D. ${ }^{\mathrm{b}}$ & 0.04 & 0.11 & 110 \\
$\mathbf{3 8}$ & 432 & 523 & 454 & 0.02 & 0.27 & 0.40 & 115 \\
$\mathbf{4 1}$ & 504 & 504 & - & 0.32 & 0.33 & - & 125 \\
$\mathbf{4 2}$ & 633 & 633 & - & 0.28 & 0.29 & - & 126 \\
\hline
\end{tabular}

a. Two discernable vibronic bands of monozinc complex. b. N.D. = Not Determined. 
We have reported four different types of fluorescent heteroditopic ligands thus far $(\mathbf{3 4}, \mathbf{3 6}-\mathbf{3 8})$; the emission wavelengths and quantum yields of their zinc(II)-free and bound forms are listed in Table 1. These compounds undergo sequential zinc(II) coordination, which alters the relaxation pathways of their fluorophores in different manners. Unraveling the metal-coordination modulated photophysical processes in these exquisitely designed molecules is intellectually satisfying. On the application side, the goal is to offer an indicator that is able to cover the zinc(II) concentration from nanomolar to millimolar range via fluorescence correlation using two emission bandpass filters on a fluorescence microscope. The structural framework embodied by compounds 36 and 37 are, in our opinion, mostly likely to achieve this objective. Both compounds are two-fluorophore systems, which provide large enough spectral separations to be analyzed by two bandpass filters. The challenge in molecular design is the selection of right pairs of zinc(II) ligands and fluorophores to maximize the dynamic ranges of the zinc(II)-sensitive emission in two channels within the desired (i.e., biologically relevant) concentration ranges.

\section{(6) Intramolecular FRET strategy}

Zinc(II)-sensitive fluorophores are being reported in growing numbers, and have been covered by numerous recent (since 2009) review articles [102, 106, 117-124]. A relatively small fraction of these compounds have been applied in fluorescence microscopy to illuminate zinc(II) ions in cellular or tissue specimens. It points to the fact that in addition to high brightness and zinc(II) sensitivity, other benchmarks have to be met in order for a zinc(II)-responding fluorescent ligand to be optimally useful in fluorescence microscopic experiments.

A fluorescent indicator needs to be photostable to endure the video time-lapse experiments for acquiring the dynamic information of an analyte during a biological event. A narrow emission 
band is preferred to allow multicolor imaging capacity. If an indicator could be used in the ratiometric mode that reduces the readout dependence on instrumental parameters and indicator loading concentration, that would also be a plus. The intramolecular FRET strategy described in this section may improve the performance of a zinc(II) indicator on these three fronts.
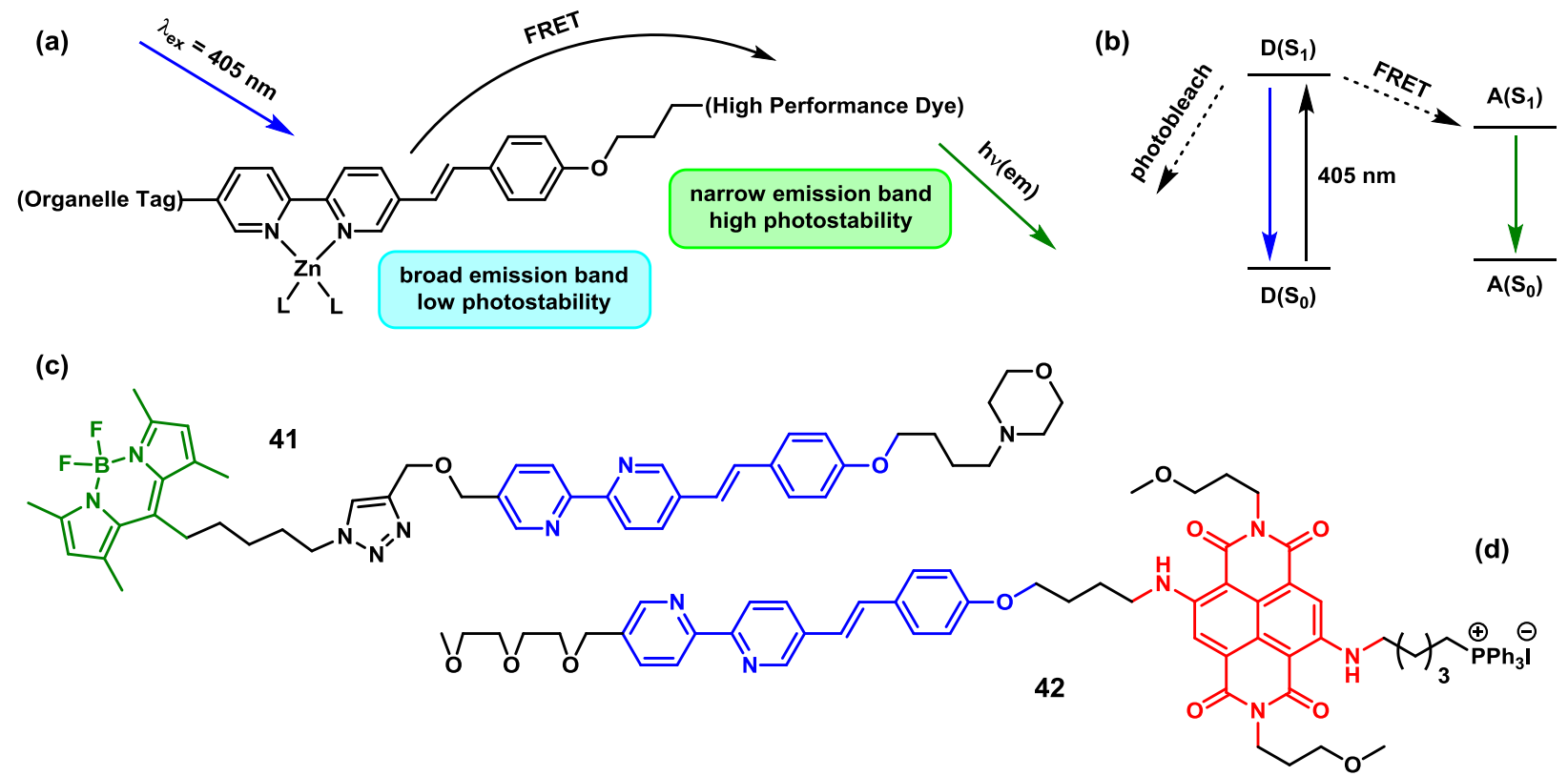

Figure 17. (a) The design of an intramolecularly FRETting zinc(II) indicator. The zinc(II)-bound AVB is the FRET donor. (b) Jablonski diagram to show how FRET (from D to A) protects a donor fluorophore from photobleaching. (c) Green FRET dye 41 [125]; and (d) red dye 42 [126].

(6a) A green, lysosome-targeting FRET-based zinc(II) indicator. In compound 41 (Figure 17), the FRET donor AVB component (blue) is sensitive to zinc(II) coordination [125]. However, it suffers from low photostability, due in part to its propensity for photoisomerization. Also, the CT emission band of the bipy-containing donor alone is inhomogeneously broadened (FWHM $=$ $3,870 \mathrm{~cm}^{-1}$ ) as a result of strong solvation, which could make it problematic in multicolor 
imaging. The intramolecular FRET from the donor to the acceptor BODIPY in $\mathbf{4 1}$ transfers the zinc(II) sensitivity of the AVB donor to the BODIPY fluorophore, in addition to reducing the bandwidth of the donor to that of BODIPY $\left(\right.$ FWHM $\left.=1,082 \mathrm{~cm}^{-1}\right)$. Moreover, the extent of trans-cis photoisomerization is significantly reduced, which can be attributed to a fast FRET that competes with donor isomerization in the excited state (Figure 17b) [125]. With a morpholino group that targets lysosomes in mammalian cells, the emission of $\mathbf{4 1}$ is shown to correlate with the zinc(II) increase in lysosomes using confocal fluorescence microscopy (Figure 18, a and b). Using two-color structured illumination microscopy (SIM) [127, 128], it is shown that 41 localizes in the interior of lysosomes of live HeLa cells, rather than anchoring on the lysosomal membranes, which are labeled by a red fluorescent protein fused with lysosome associated membrane protein (Figure 19).

The rigorous characterization of the intramolecular FRET in 41 (using a methoxy analog) is carried out using femtosecond time-resolved transient absorption spectroscopy [66]. The decay time constant of FRET is $41 \mathrm{ps}$ in acetonitrile. This value increases as the medium becomes more polar, which is consistent with the Förster-type resonance energy transfer that is based on excited state dipole/dipole interactions and is consequently attenuated by solvent dipoles. The solventrelaxation of the donor $\mathrm{CT}$ excited state occurs on the same time scale as FRET, but can be distinguished by the opposite solvent polarity dependency [66]. 

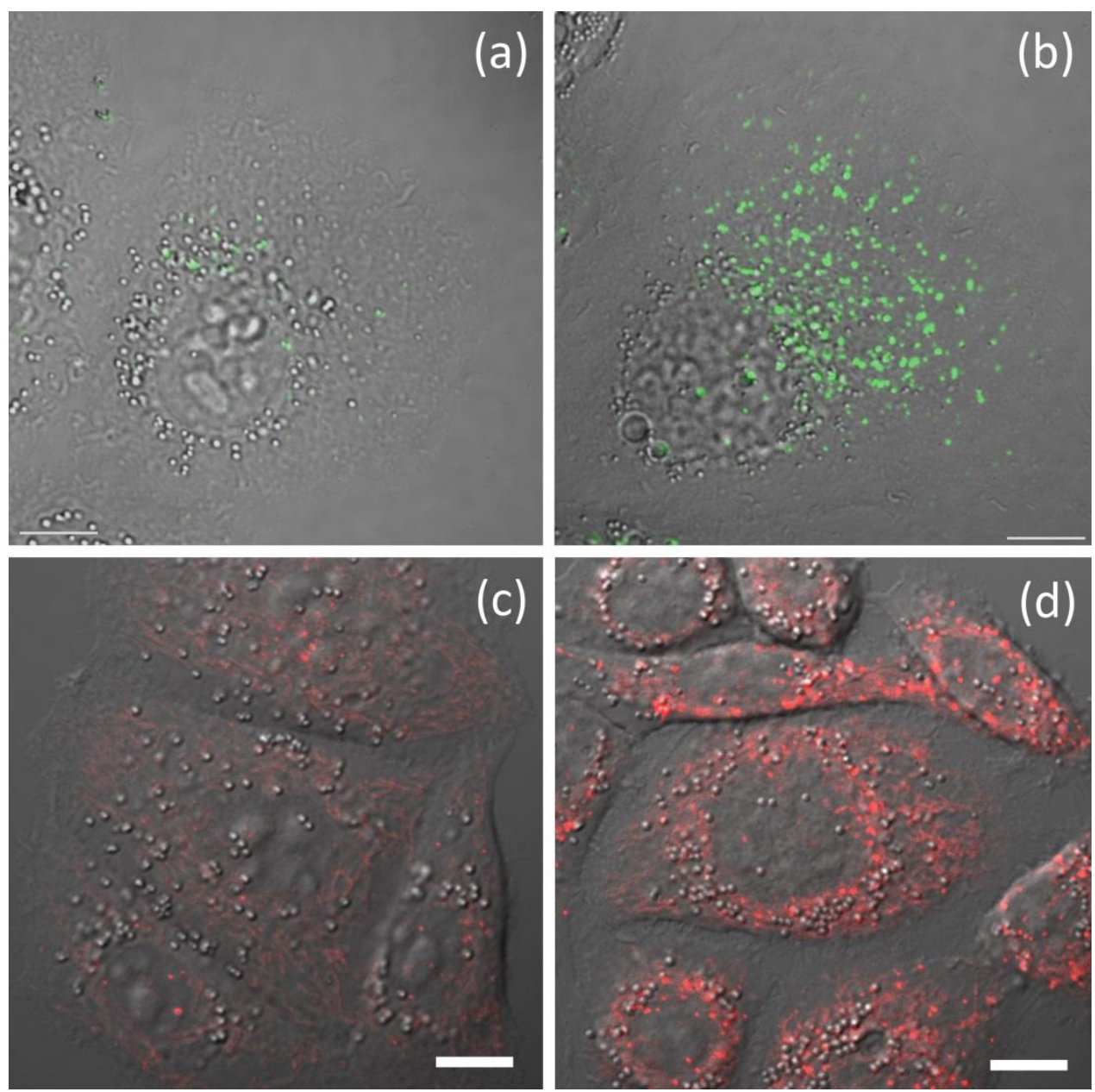

Figure 18. The overlay of differential interference contrast (DIC) and fluorescence images of HeLa cells that contain (a) compound 41 with no supplemental $\mathrm{ZnCl}_{2}$, (b) 41 in the presence of $50 \mu \mathrm{M}$ of $\mathrm{ZnCl}_{2}$, (c) compound 42 with no supplemental $\mathrm{ZnCl}_{2}$, and (d) 42 in the presence of 50 $\mu \mathrm{M}$ of $\mathrm{ZnCl}_{2}$. The excitation source is a $405-\mathrm{nm}$ diode laser. Emission window: $500-530 \mathrm{~nm}$ for panels (a) and (b); 580-680 nm for panels (c) and (d). Scale bar: $10 \mu \mathrm{m}$. Panels (a) and (b) are reproduced from Ref. 125 with permission from John Wiley and Sons; panels (c) and (d) are reproduced from Ref. 126 with permission from The Royal Society of Chemistry. 

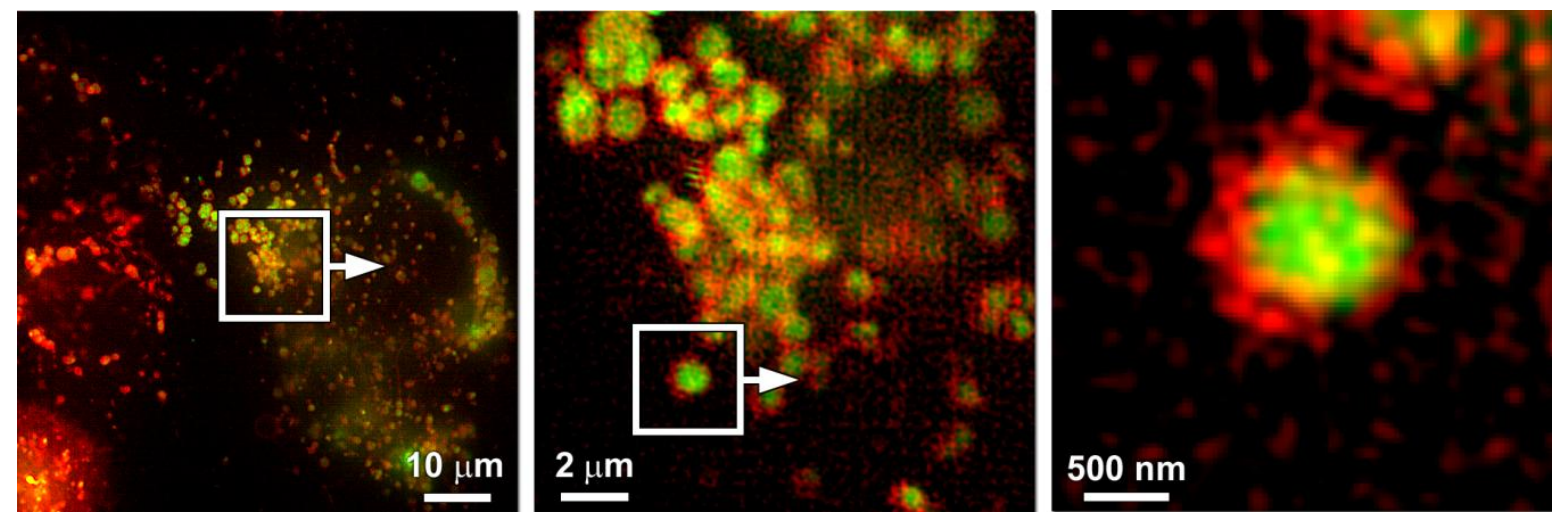

Figure 19. Localization of compound 41 (green) compared to that of a lysosome-associated membrane protein fused to the fluorescent protein FusionRed (red). Green: 495-550 nm; red: 570-620 nm. Reproduced from Ref. 125 with permission from John Wiley and Sons.

(6b) A red, mitochondria-targeting FRET-based zinc(II) indicator. Another example of the FRET strategy is compound $\mathbf{4 2}$ (Figure 17d), in which the diamino-substituted naphthalenediimide (NDI) is the acceptor fluorophore [126]. Therefore, this compound exhibits zinc(II)-dependent red fluorescence. The triphenylphosphonium (TPP) moiety directs the compound to mitochondria of mammalian cells so that the organellar-specific zinc(II) signals could be recorded (Figure 18, c and d). One may envision that the co-administration of 41 and 42, which have identical zinc(II)-responding fluoroionophores but FRET acceptors of different colors and localization tags for different subcellular targets, may reveal the correlated changes of zinc(II) ions in different organelles.

\section{(7) Summary and Outlook}

When bipy and a fluorophore are non-conjugatively connected, the bipy/zinc(II) complex often acts as an electron acceptor from an excited fluorophore, by which the emission is quenched. If 
bipy is conjugated with another $\pi$ system, e.g., an arylvinyl moiety as described in this work, the coordination with zinc(II) often elicits a bathochromic shift of emission because in the zinc(II) complex the excited state polarizing toward the bipy end is being stabilized. The restriction of single bond rotation upon zinc(II) coordination might have contributed to the uncompromised fluorescence quantum yields of the zinc(II) complexes of these fluorophores. The sensitivity of AVB ligands to zinc(II) has been utilized to develop fluorescent indicators for this ion. However, AVBs are prone to photoisomerization, and the emission of AVBs is broad due to the strong solvent-solute interactions that a large excited state dipole enjoys. The zinc(II) sensitivity of AVBs can be preserved, their emission width be reduced, and their photostability be increased, by employing an intramolecular FRET strategy. Our group has also incorporated AVBs in heteroditopic ligand structures to afford fluorescent compounds that are responsive to zinc(II) concentration changes over broad ranges. The lessons learned from the zinc(II)-sensitive AVBs and the efforts to transform them into indicators useful in fluorescence imaging of intracellular zinc(II) ions could conceivably be applied in indicator designs targeting other analytes.

\section{Present Address}

$\S$ Institute of Organic Chemistry and Biochemistry, Academy of Sciences of the Czech Republic, 16610 Prague 6, Czech Republic

\section{ACKNOWLEDGMENT}

This research has been supported by the National Institutes of Health (GM081382) and the National Science Foundation (CHE0809201, CHE1213574). We are grateful to Prof. Ken Knappenberger (FSU Chemistry and Biochemistry) on the collaboration in photophysical 
characterizations of the fluorescent ligands and complexes, in particular the application of femtosecond time-resolved transient absorption spectroscopy. We thank Prof. Cathy Levenson (FSU College of Medicine) for offering guidance on the biology of zinc. We are particularly indebted to Mike Davidson and his coworkers Chris Murphy, John Allen, and Michelle Baird at the National High Magnetic Field Laboratory for providing expertise on the fluorescence microscopy front of this work over the past seven years.

\section{REFERENCES}

[1] E.C. Constable, Homoleptic Complexes of 2,2'-Bipyridine, Adv. Inorg. Chem., 34 (1989) $1-63$.

[2] C. Kaes, A. Katz, M.W. Hosseini, Bipyridine: The Most Widely Used Ligand. A Review of Molecules Comprising at Least Two 2,2'-Bipyridine Units, Chem. Rev., 100 (2000) 3553-3590.

[3] E.F. Kassierer, A.S. Kertes, Synergic Extraction of Some Lanthanides and Transition Metals by Two Bidentate Chelating Agents, J. Inorg. Nucl. Chem., 34 (1972) 3221-3231.

[4] K. Kavallieratos, J.M. Rosenberg, J.C. Bryan, Pb(II) Coordination and Synergistic IonExchange Extraction by Combinations of Sulfonamide Chelates and 2,2'-Bipyridine, Inorg. Chem., 44 (2005) 2573-2575.

[5] J.-S. Wang, K. Matyjaszewski, Controlled "Living" Radical Polymerization. Atom Transfer Radical Polymerization in the Presence of Transition-Metal Complexes, J. Am. Chem. Soc., 117 (1995) 5614-5615. 
[6] C. Schneider, A.R. Sreekanth, E. Mai, Scandium-Bipyridine-Catalyzed Enantioselective Addition of Alcohols and Amines to meso-Epoxides, Angew. Chem. Int. Ed., 43 (2004) 56915694.

[7] D.A. Nicewicz, D.W.C. MacMillan, Merging Photoredox Catalysis with Organocatalysis: The Direct Asymmetric Alkylation of Aldehydes, Science, 322 (2008) 77-80.

[8] M. Bourrez, F. Molton, S. Chardon-Noblat, A. Deronzier, [Mn(bipyridyl)(CO) $\left.{ }_{3} \mathrm{Br}\right]$ : An Abundant Metal Carbonyl Complex as Efficient Electrocatalyst for $\mathrm{CO}_{2}$ Reduction, Angew. Chem. Int. Ed., 50 (2011) 9903-9906.

[9] Y. Hayashi, S. Santoro, Y. Azuma, F. Himo, T. Ohshima, K. Mashima, Enzyme-Like Catalysis via Ternary Complex Mechanism: Alkoxy-Bridged Dinuclear Cobalt Complex Mediates Chemoselective O-Esterification over N-Amidation, J. Am. Chem. Soc., 135 (2013) 6192-6199.

[10] F.W. Cagle, G.F. Smith, 2,2'-Bipyridine Ferrous Complex Ion as Indicator in Determination of Iron, Anal. Chem., 19 (1947) 384-385.

[11] L.L. Stookey, Ferrozine-A New Spectrophotometric Reagent for Iron, Anal. Chem., 42 (1970) 779-781.

[12] K. Kalyanasundaram, Photophysics, photochemistry and solar energy conversion with tris(bipyridyl)ruthenium(II) and its analogues, Coord. Chem. Rev., 46 (1982) 159-244.

[13] B. O'Regan, M. Grätzel, A Low-Cost, High-Efficiency Solar Cell Based on DyeSensitized Colloidal $\mathrm{TiO}_{2}$ Films, Nature, 353 (1991) 737-740. 
[14] M.K. Nazeeruddin, A. Kay, I. Rodicio, R. Humphry-Baker, E. Muller, P. Liska, N. Vlachopoulos, M. Grätzel, Conversion of Light to Electricity by cis- $\mathrm{X}_{2} \operatorname{Bis}\left(2,2^{\prime}\right.$-bipyridyl-4,4'dicarboxylate)ruthenium(II) Charge-Transfer Sensitizers $\left(\mathrm{X}=\mathrm{Cl}^{-}, \mathrm{Br}^{-}, \mathrm{I}^{-}, \mathrm{CN}^{-}\right.$, and $\left.\mathrm{SCN}^{-}\right)$on Nanocrystalline $\mathrm{TiO}_{2}$ Electrodes, J. Am. Chem. Soc., 115 (1993) 6382-6390.

[15] R.A. Palmer, T.S. Piper, 2,2'-Bipyridine Complexes. I. Polarized Crystal Spectra of Tris(2,2'-bipyridine)copper(II), -nickel(II), -cobalt(II), -iron(II), and -ruthenium(II), Inorg. Chem., 5 (1966) 864-878.

[16] G.A. Crosby, Spectroscopic Investigations of Excited States of Transition-Metal Complexes, Acc. Chem. Res., 8 (1975) 231-238.

[17] P.S. Braterman, J.-I. Song, R.D. Peacock, Electronic Absorption Spectra of the Iron(II) Complexes of 2,2'-Bipyridine, 2,2'-Bipyrimidine, 1,10-Phenanthroline, and 2,2':6',2''Terpyridine and Their Reduction Products, Inorg. Chem., 31 (1992) 555-559.

[18] H. Rensmo, S. Lunell, H. Siegbahn, Absorption and electrochemical properties of ruthenium(II) dyes, studied by semiempirical quantum chemical calculations, J. Photochem. Photobiol. A: Chem, 114 (1998) 117-124.

[19] J. Rebek, Jr., J.E. Trend, On Binding to Transition States and Ground States: Remote Catalysis, J. Am. Chem. Soc., 100 (1978) 4315-4316.

[20] J. Rebek, Jr., J.E. Trend, R.V. Wattley, S. Chakravorti, Allosteric Effects in Organic Chemistry. Site-Specific Binding, J. Am. Chem. Soc., 101 (1979) 4333-4337.

[21] C. Bolm, M. Zehnder, D. Bur, Optically Active Bipyridines in Asymmetric Catalysis, Angew. Chem. Int. Ed. Engl., 29 (1990) 205-207. 
[22] T.R. Kelly, M.C. Bowyer, K.V. Bhaskar, D. Bebbington, A. Garcia, F. Lang, M.H. Kim, M.P. Jette, A Molecular Brake, J. Am. Chem. Soc., 116 (1994) 3657-3658.

[23] N.H. Damrauer, G. Cerullo, A. Yeh, T.R. Boussie, C.V. Shank, J.K. McCusker, Femtosecond Dynamics of Excited-State Evolution in $\left[\mathrm{Ru}(\mathrm{bpy})_{3}\right]^{2+}$, Science, 275 (1997) 54-57.

[24] K. Kalyanasundaram, M. Grätzel, Applications of Functionalized Transition Metal Complexes in Photonic and Optoelectronic Devices, Coord. Chem. Rev., 77 (1998) 347-414.

[25] K. Matyjaszewski, S.M. Jo, H.-j. Paik, D.A. Shipp, An Investigation into the CuX/2,2'Bipyridine (X ) Br or $\mathrm{Cl}$ ) Mediated Atom Transfer Radical Polymerization of Acrylonitrile, Macromolecules, 32 (1999) 6431-6438.

[26] G.R. Newkome, A.K. Patri, E. Holder, U.S. Schubert, Synthesis of 2,2'-Bipyridines: Versatile Building Blocks for Sexy Architectures and Functional Nanomaterials, Eur. J. Org. Chem., (2004) 235-254.

[27] A.T. Yeh, C.V. Shank, J.K. McCusker, Ultrafast Electron Localization Dynamics Following Photo-Induced Charge Transfer, Science, 289 (2000) 935-938.

[28] T.M. Boller, J.M. Murphy, M. Hapke, T. Ishiyama, N. Miyaura, J.F. Hartwig, Mechanism of the Mild Functionalization of Arenes by Diboron Reagents Catalyzed by Iridium Complexes. Intermediacy and Chemistry of Bipyridine-Ligated Iridium Trisboryl Complexes, J. Am. Chem. Soc., 127 (2005) 14263-14278.

[29] V. Balzani, G. Bergamini, F. Marchioni, P.C. Balzani, G. Bergamini, F. Marchioni, P. Ceroni, Ru(II)-bipyridine complexes in supramolecular systems, devices and machines, Coord. Chem. Rev., 250 (2006) 1254-1266. 
[30] F.N. Castellano, I.E. Pomestchenko, E. Shikhova, F. Hua, M.L. Muro, N. Rajapakse, Photophysics in bipyridyl and terpyridyl platinum(II) acetylides, Coord. Chem. Rev., 250 (2006) 1819-1828.

[31] M. Hapke, L. Brandt, A. Lützen, Versatile tools in the construction of substituted 2,2'bipyridines-cross-coupling reactions with tin, zinc and boron compounds, Chem. Soc. Rev., 37 (2008) 2782-2797.

[32] L.-1. Tian, C. Wang, S. Dawn, M.D. Smith, J.A. Krause, L.S. Shimizu, Macrocycles with Switchable exo/endo Metal Binding Sites, J. Am. Chem. Soc., 131 (2009) 17620-17629.

[33] K.M. Lancaster, J.B. Gerken, A.C. Durrell, J.H. Palmer, H.B. Gray, Electronic structures, photophysical properties, and electrochemistry of ruthenium(II)(bpy) $)_{2}$ pyridylimidazole complexes, Coord. Chem. Rev., 254 (2010) 1803-1811.

[34] B. Happ, A. Winter, M.D. Hager, U.S. Schubert, Photogenerated avenues in macromolecules containing $\operatorname{Re}(\mathrm{I}), \operatorname{Ru}(\mathrm{II}), \mathrm{Os}(\mathrm{II})$, and $\operatorname{Ir}(\mathrm{III})$ metal complexes of pyridine-based ligands, Chem. Soc. Rev., 41 (2012) 2222-2255.

[35] T. Morimoto, C. Nishiura, M. Tanaka, J. Rohacova, Y. Nakagawa, Y. Funada, K. Koike, Y. Yamamoto, S. Shishido, T. Kojima, T. Saeki, T. Ozeki, O. Ishitani, Ring-Shaped Re(I) Multinuclear Complexes with Unique Photofunctional Properties, J. Am. Chem. Soc., 135 (2013) 13266-13269.

[36] L. Li, M. Zeng, S.B. Herzon, Broad-Spectrum Catalysts for the Ambient Temperature Anti-Markovnikov Hydration of Alkynes, Angew. Chem. Int. Ed., 53 (2014) 7892-7895. 
[37] W. Zhang, R. Alonso-Mori, U. Bergmann, C. Bressler, M. Chollet, A. Galler, W. Gawelda, R.G. Hadt, R.W. Hartsock, T. Kroll, K.S. Kjær, K. Kubiček, H.T. Lemke, H.W. Liang, D.A. Meyer, M.M. Nielsen, C. Purser, J.S. Robinson, E.I. Solomon, Z. Sun, D. Sokaras, T.B.v. Driel, G. Vankó, T.-C. Weng, D. Zhu, K.J. Gaffney, Tracking excited-state charge and spin dynamics in iron coordination complexes, Nature, 509 (2014) 345-348.

[38] J. Gu, Y. Yan, B.J. Helbig, Z. Huang, T. Lian, R.H. Schmehl, The influence of ligand localized excited states on the photophysics of second row and third row transition metal terpyridyl complexes: Recent examples and a case study, Coord. Chem. Rev., 282-283 (2015) 100-109.

[39] J.D. Knoll, C. Turro, Control and utilization of ruthenium and rhodium metal complex excited states for photoactivated cancer therapy, Coord. Chem. Rev., 282-283 (2015) 110-126.

[40] A.P. de Silva, I.M. Dixon, H.Q.N. Gunaratne, T. Gunnlaugsson, P.R.S. Maxwell, T.E. Rice, Integration of Logic Functions and Sequential Operation of Gates at the Molecular-Scale, J. Am. Chem. Soc., 121 (1999) 1393-1394.

[41] J.-E.S. Sohna, P. Jaumier, F. Fages, Zinc(II)-driven Fluorescence Quenching of a Pyrenelabelled Bis-2,2'-bipyridine Ligand, J. Chem. Res., (1999) 134-135.

[42] A.L. Rodriguez, G. Peron, Christine Duprat, M. Vailier, E. Fouquet, F. Fages, The Use of a Monoorganotin Derivative of Pyrene in the Palladium(0)-Catalyzed Synthesis of a New MetalCation Complexing Molecule Displaying Excited State Charge Transfer Properties, Tetrahedron Lett., 39 (1998) 1179-1182. 
[43] T. Ueno, Y. Urano, K.-i. Setsukinai, H. Takakusa, H. Kojima, K. Kikuchi, K. Ohkubo, S. Fukuzumi, T. Nagano, Rational Principles for Modulating Fluorescence Properties of Fluorescein, J. Am. Chem. Soc., 126 (2004) 14079-14085.

[44] A. Ajayaghosh, P. Carol, S. Sreejith, A Ratiometric Fluorescence Probe for Selective Visual Sensing of $\mathrm{Zn}^{2+}$, J. Am. Chem. Soc., 127 (2005) 14962-14963.

[45] S. Leroy, T. Soujanya, F. Fages, Zinc(II)-Operated Intramolecular Charge Transfer Fluorescence Emission in Pyrene-2,2'-bipyridine Conjugated Molecular Rods, Tetrahedron Lett., 42 (2001) 1665-1667.

[46] L.X. Chen, W.J.H. Jäger, D.J. Gosztola, M.P. Niemczyk, M.R. Wasielewski, Ionochromic Effects and Structures of Metalated Poly(p-phenylenevinylene) Polymers Incorporating 2,2'Bipyridines, J. Phys. Chem. B, 104 (2000) 1950-1960.

[47] X.-y. Wang, A.D. Guerzo, R.H. Schmehl, Preferential Solvation of an ILCT Excited State in Bis(terpyridine-phenylene-vinylene) Zn(II) Complexes, Chem. Commun., (2002) 2344-2345.

[48] A. Abbotto, L. Bellotto, F.D. Angelis, N. Manfredi, C. Marinzi, Heteroaromatic DonorAcceptor $\pi$-Conjugated 2,2'-Bipyridines, Eur. J. Org. Chem., (2008) 5047-5054.

[49] K.P. Divya, S. Sreejith, B. Balakrishna, P. Jayamurthy, P. Anees, A. Ajayaghosh, A Zn ${ }^{2+}$ specific fluorescent molecular probe for the selective detection of endogenous cyanide in biorelevant samples, Chem. Commun., 46 (2010) 6069-6071.

[50] S. Sreejith, K.P. Divya, P. Jayamurthy, J. Mathew, V.N. Anupama, D.S. Philips, P. Anees, A. Ajayaghosh, Heteroaromatic donors in donor-acceptor-donor based fluorophores facilitate zinc ion sensing and cell imaging, Photochem. Photobiol. Sci., 11 (2012) 1715-1723. 
[51] M. Sarma, T. Chatterjee, S. Ghanta, S.K. Das, D- $\pi$-A-A- $\pi$-D Prototype 2,2'-Bipyridine Dyads Exhibiting Large Structure and Environment-Sensitive Fluorescence: Synthesis, Photophysics, and Computation, J. Org. Chem., 77 (2012) 432-444.

[52] K.P. Divya, S. Sreejith, P. Ashokkumar, K. Yuzhan, Q. Peng, S.K. Maji, Y. Tong, H. Yu, Y. Zhao, P. Ramamurthy, A. Ajayaghosh, A ratiometric fluorescent molecular probe with enhanced two-photon response upon $\mathrm{Zn}^{2+}$ binding for in vitro and in vivo bioimaging, Chem. Sci., 5 (2014) 3469-3474.

[53] A.H. Younes, L. Zhang, R.J. Clark, L. Zhu, Fluorescence of 5-Arylvinyl-5'-Methyl-2,2'Bipyridyl Ligands and Their Zinc Complexes, J. Org. Chem., 74 (2009) 8761-8772.

[54] J.R. Lakowicz, Solvent and Environmental Effects, in: Principles of Fluorescence Spectroscopy, Springer, 2006, pp. 205-235.

[55] P. Suppan, N. Ghoneim, Solvatochromism, The Royal Society of Chemistry, 1997.

[56] B. Valeur, Effect of Polarity on Fluorescence Emission. Polarity Probes, in: Molecular Fluorescence. Principles and Applications, WILEY-VCH, 2002, pp. 200-225.

[57] C. Reichardt, T. Welton, Solvent Effects on the Absorption Spectra of Organic Compounds, in: Solvents and Solvent Effects in Organic Chemistry, Wiley-VCH, 2010.

[58] A. Painelli, F. Terenziani, Optical Spectra of Push-Pull Chromophores in Solution: A Simple Model, J. Phys. Chem. A, 104 (2000) 11041-11048.

[59] E.M. Kosower, Intramolecular Donor-Acceptor Systems. 9. Photophysics of (Phenylamino)naphthalenesulfonates: A Paradigm for Excited-State Intramolecular Charge Transfer, Acc. Chem. Res., 15 (1982) 259-266. 
[60] S.A. Kovalenko, N.P. Ernsting, J. Ruthmann, Femtosecond hole-burning spectroscopy of the dye DCM in solution: the transition from the locally excited to a charge-transfer state, Chem. Phys. Lett., 258 (1996) 445-454.

[61] Z.R. Grabowski, K. Rotkiewicz, W. Rettig, Structural Changes Accompanying Intramolecular Electron Transfer: Focus on Twisted Intramolecular Charge-Transfer States and Structures, Chem. Rev., 103 (2003) 3899-4031.

[62] C. Sissa, V. Calabrese, M. Cavazzini, L. Grisanti, F. Terenziani, S. Quici, A. Painelli, Tuning the Nature of the Fluorescent State: A Substituted Polycondensed Dye as a Case Study, Chem. Eur. J., 19 (2013) 924-935.

[63] S. Olsen, Locally-Excited (LE) versus Charge-Transfer (CT) Excited State Competition in a Series of Para-Substituted Neutral Green Fluorescent Protein (GFP) Chromophore Models, J. Phys. Chem. B, 119 (2015) 2566-2575.

[64] N.J. Turro, Modern Molecular Photochemistry, University Science Books, Sausalito, CA, 1991.

[65] This shift can be considered as the constant term in the Lippert-Mataga equation.

[66] K. Sreenath, C. Yi, J.K.L. Knappenberger, L. Zhu, Distinguishing Förster Resonance Energy Transfer and Solvent-Mediated Charge-Transfer Relaxation Dynamics in a Zinc(II) Indicator: A Femtosecond Time-Resolved Transient Absorption Spectroscopic Study, Phys. Chem. Chem. Phys., 16 (2014) 5088-5092.

[67] N. Mataga, Y. Kaifu, M. Koizumi, Solvent Effects upon Fluorescence Spectra and the Dipolemoments of Excited Molecules, Bull. Chem. Soc. Jpn., 29 (1956) 465-470. 
[68] B. Koutek, Dipole moments in excited state. Statistical investigation of methods employing solvatochromism, Collect. Czech. Chem. Commun., 43 (1978) 2368-2386.

[69] M. Ravi, A. Samanta, T.P. Radhakrishnan, Excited State Dipole Moments from an Efficient Analysis of Solvatochromic Stokes Shift Data, J. Phys. Chem., 98 (1994) 9133-9136.

[70] A. Painelli, F. Terenziani, A non-perturbative approach to solvatochromic shifts of pushpull chromophores, Chem. Phys. Lett., 312 (1999) 211-220.

[71] W. Rettig, Charge Separation in Excited States of Decoupled Systems - TICT Compounds and Implications Regarding the Development of New Laser Dyes and the Primary Process of Vision and Photosynthesis, Angew. Chem., Int. Ed. Engl., 25 (1986) 971-988.

[72] T.S. Singh, S. Mitra, A.K. Chandra, N. Tamai, S. Kar, A Combined Experimental and Theoretical Study on Photoinduced Intramolecular Charge Transfer in trans-Ethyl p(Dimethylamino)cinamate, J. Photochem. Photobiol. A: Chem, 197 (2008) 295-305.

[73] G. Pistolis, A. Malliaris, Effect of substituents on the spectroscopic properties of all-trans1,6-diphenyl-1,3,5-hexatriene, Chem. Phys., 226 (1998) 83-99.

[74] B.C. Lobo, C.J. Abelt, Does PRODAN Possess a Planar or Twisted Charge-Transfer Excited State? Photophysical Properties of Two PRODAN Derivatives, J. Phys. Chem. A, 107 (2003) 10938-10943.

[75] A.R. Katritzky, D.-W. Zhu, K.S. Schanze, Intramolecular Charge Transfer Properties of Dicyanovinyl-Substituted Aromatics, J. Phys. Chem., 95 (1991) 5137-5142. 
[76] Z. Diwu, Y. Lu, C. Zhang, D.H. Klaubert, R.P. Haugland, Fluorescent Molecular Probes II. The Synthesis, Spectral Properties and Use of Fluorescent Solvatochromic Dapoxyl Dyes, PHotochem. Photobiol., 66 (1997) 424-431.

[77] L.L. Merritt, E. Schroeder, The crystal structure of 2,2'-bipyridine, Acta Cryst., 9 (1956) 801-804.

[78] A. Göller, U.-W. Grummt, Torsional Barriers in Biphenyl, 2,2'-Bipyridine and 2Phenylpyridine, Chem. Phys. Lett., 321 (2000) 399-405.

[79] A.H. Younes, L. Zhang, R.J. Clark, M.W. Davidson, L. Zhu, Electronic structural dependence of the photophysical properties of fluorescent heteroditopic ligands - implications in designing molecular fluorescent indicators, Org. Biomol. Chem., 8 (2010) 5431-5441.

[80] H.S. Joshi, R. Jamshidi, Y. Tor, Conjugated 1,10-Phenanthrolines as Tunable Fluorophores, Angew. Chem. Int. Ed., 38 (1999) 2722-2725.

[81] N. Mataga, Y. Murata, Electron Donor-Acceptor Interactions in the Fluorescent State of Tetracyanobenzene-Aromatic Hydrocarbon Complexes, J. Am. Chem. Soc., 91 (1969) 31443152.

[82] R. Englman, J. Jortner, The energy gap law for radiationless transitions in large molecules, Mol. Phys., 18 (1970) 145-164.

[83] K.F. Freed, J. Jortner, Multiphonon Processes in the Nonradiative Decay of Large Molecules, J. Chem. Phys., 52 (1970) 6272-6291. 
[84] Z. Yuan, A.H. Younes, J.R. Allen, M.W. Davidson, L. Zhu, Enhancing the Photostability of Arylvinylbipyridyl Compounds as Fluorescent Indicators for Intracellular Zinc(II) Ions, $J$. Org. Chem., Revision under review.

[85] The bipy/zinc(II) complex has been reported to have low cytotoxicity. See: Y. Shi, B.B. Toms, N. Dixit, N. Kumari, L. Mishra, J. Goodisman, J.C. Dabrowiak, Cytotoxicity of Cu(II) and Zn(II) 2,2'-Bipyridyl Complexes: Dependence of IC50 on Recovery Time, Chem. Res. Toxicol., 23 (2010) 1417-1426.

[86] G.H. Eom, H.M. Park, M.Y. Hyun, S.P. Jang, C. Kim, J.H. Lee, S.J. Lee, S.-J. Kim, Y. Kim, Anion effects on the crystal structures of $\mathrm{Zn}^{\mathrm{II}}$ complexes containing 2,2'-bipyridine: Their photoluminescence and catalytic activities, Polyhedron, 30 (2011) 1555-1564.

[87] D.N. Kozhevnikov, O.V. Shabunina, D.S. Kopchuk, P.A. Slepukhin, V.N. Kozhevnikov, 5-Aryl-2,2'-Bipyridines as Tunable Fluorophores, Tetrahedron Lett., 47 (2006) 7025-7029.

[88] P.V. James, K. Yoosaf, J. Kumar, K.G. Thomas, A. Listorti, G. Accorsi, N. Armaroli, Tunable photophysical properties of phenyleneethynylene based bipyridine ligands, Photochem. Photobiol. Sci., 8 (2009) 1432-1440.

[89] A.E. Dennis, R.C. Smith, "Turn-on" Fluorescent Sensor for the Selective Detection of Zinc Ion by a Sterically-Encumbered Bipyridyl-Based Receptor, Chem. Commun., (2007) 46414643.

[90] Y. Sun, S. Wang, Extending $\pi$-Conjugation of Triarylborons with a 2,2'-Bpy Core: Impact of Donor-Acceptor Geometry on Luminescence, Anion Sensing, and Metal Ion Binding, Inorg. Chem., 49 (2010) 4394-4404. 
[91] X. Peng, Y. Xu, S. Sun, Y. Wu, J. Fan, A Ratiometric Fluorescent Sensor for Phosphates:

$\mathrm{Zn}^{2+}$-Enhanced ICT and Ligand Competition, Org. Biomol. Chem., 5 (2007) 226-228.

[92] C. Goze, G. Ulrich, L. Charbonniere, M. Cesario, T. Prange, R. Ziessel, Cation Sensors Based on Terpyridine-Functionalized Boradiazaindacene, Chem. Eur. J., 9 (2003) 3748-3755.

[93] W. Goodall, J.A.G. Williams, A new, highly fluorescent terpyridine which responds to zinc ions with a large red-shift in emission, Chem. Commun., (2001) 2514-2515.

[94] G. Bergamini, L. Boselli, P. Ceroni, P. Manca, G. Sanna, M. Pilo, Terthiophene Appended with Terpyridine Units as Receptors for Protons and $\mathrm{Zn}^{2+}$ Ions: Photoinduced Energy and Electron Transfer Processes, Eur. J. Inorg. Chem., (2011) 4590-4595.

[95] Compound 25 lacks a vinyl or alkynyl type $\pi$ bridge.

[96] J.C. Loren, J.S. Siegel, Synthesis and Fluorescence Properties of Manisyl-Substituted Terpyridine, Bipyridine, and Phenanthroline, Angew. Chem. Int. Ed., 40 (2000) 754-757.

[97] L. Zhu, L. Zhang, A.H. Younes, Mini Review: Fuorescent Heteroditopic Ligands of Metal Ions, Supramol. Chem., 21 (2009) 268-283.

[98] C.E. Outten, T.V. O'Halloran, Femtomolar Sensitivity of Metalloregulatory Proteins Controlling Zinc Homeostasis, Science, 292 (2001) 2488-2492.

[99] C.J. Frederickson, J.-Y. Koh, A.I. Bush, The Neurobiology of Zinc in Health and Disease, Nat. Rev. Neurosci., 6 (2005) 449-462.

[100] R.A. Colvin, W.R. Holmes, C.P. Fontaine, W. Maret, Cytosolic zinc buffering and muffling: Their role in intracellular zinc homeostasis, Metallomics, 2 (2010) 306-317. 
[101] A.P. de Silva, H.Q.N. Gunaratne, T. Gunnlaugsson, A.J.M. Huxley, C.P. McCoy, J.T. Rademacher, T.E. Rice, Signaling Recognition Events with Fluorescent Sensors and Switches, Chem. Rev., 97 (1997) 1515-1566.

[102] L. Zhu, Z. Yuan, K. Sreenath, J.T. Simmons, Zn(II)-coordination modulated ligand photophysical processes - the development of fluorescent indicators for imaging biological Zn(II) ions, RSC Adv., 4 (2014) 20398-20440.

[103] L. Zhang, R.J. Clark, L. Zhu, A Heteroditopic Fluoroionophoric Platform for Constructing Fluorescent Probes with Large Dynamic Ranges for Zinc Ions, Chem. Eur. J., 14 (2008) 2894-2903.

[104] B. Valeur, I. Leray, Design Principles of Fluorescent Molecular Sensors for Cation Recognition, Coord. Chem. Rev., 205 (2000) 3-40.

[105] A.P. de Silva, T.S. Moody, G.D. Wright, Fluorescent PET (Photoinduced Electron Transfer) Sensors as Potent Analytical Tools, Analyst, 134 (2009) 2385-2393.

[106] Z. Xu, J. Yoon, D.R. Spring, Fluorescent Chemosensors for $\mathrm{Zn}^{2+}$, Chem. Soc. Rev., 39 (2010) 1996-2006.

[107] G.-C. Kuang, J.R. Allen, M.A. Baird, B.T. Nguyen, L. Zhang, T.J.J. Morgan, C.W. Levenson, M.W. Davidson, L. Zhu, Balance between Fluorescence Enhancement and Association Affinity in Fluorescent Heteroditopic Indicators for Imaging Zinc Ion in Living Cells, Inorg. Chem., 50 (2011) 10493-10504.

[108] D.B. Murphy, M.W. Davidson, Fundamentals of Light Microscopy and Electronic Imaging, Second ed., Wiley-Blackwell, Hoboken, NJ, 2013. 
[109] R.J. Wandell, A.H. Younes, L. Zhu, Metal-Coordination Mediated Sequential ChelationEnhanced Fluorescence (CHEF) and Fluorescence Resonance Energy Transfer (FRET) in a Heteroditopic Ligand System, New J. Chem., 34 (2010) 2176-2182.

[110] K. Sreenath, R.J. Clark, L. Zhu, Tricolor Emission of a Fluorescent Heteroditopic Ligand over a Concentration Gradient of Zinc(II) Ions, J. Org. Chem., 77 (2012) 8268-8279.

[111] H.N. Kim, M.H. Lee, H.J. Kim, S.K. Kim, J. Yoon, A New Trend in Rhodamine-Based Chemosensors: Application of Spirolactam Ring-Opening to Sensing Ions, Chem. Soc. Rev., 37 (2008) 1465-1472.

[112] D.T. Quang, J.S. Kim, Fluoro- and Chromogenic Chemodosimeters for Heavy Metal Ion Detection in Solution and Biospecimens, Chem. Rev., 110 (2010) 6280-6301.

[113] M.E. Jun, B. Roy, K.H. Ahn, “Turn-on” fluorescent sensing with "reactive” probes, Chem. Commun., 47 (2011) 7583-7601.

[114] X. Chen, T. Pradhan, F. Wang, J.S. Kim, J. Yoon, Fluorescent Chemosensors Based on Spiroring-Opening of Xanthenes and Related Derivatives, Chem. Rev., 112 (2012) 1910-1956.

[115] A.Y. Younes, L. Zhu, Tunable Dual Fluorescence of 3-(2,2'-Bipyridyl)-Substituted Iminocoumarin, ChemPhysChem, 13 (2012) 3827-3835.

[116] This structure was also acquired after the publication of ref. 115 .

[117] R. McRae, P. Bagchi, S. Sumalekshmy, C.J. Fahrni, In Situ Imaging of Metals in Cells and Tissues, Chem. Rev., 109 (2009) 4780-4827. 
[118] E.M. Nolan, S.J. Lippard, Small-Molecule Fluorescent Sensors for Investigating Zinc Metalloneurochemistry, Acc. Chem. Res., 42 (2009) 193-203.

[119] E. Tomat, S.J. Lippard, Imaging Mobile Zinc in Biology, Curr. Opin. Chem. Biol., 14 (2010) 225-230.

[120] M.D. Pluth, E. Tomat, S.J. Lippard, Biochemistry of Mobile Zinc and Nitric Oxide Revealed by Fluorescent Sensors, Annu. Rev. Biochem., 80 (2011) 333-355.

[121] Z. Huang, S.J. Lippard, Illuminating Mobile Zinc with Fluorescence: From Cuvettes to Live Cells and Tissues, Methods in Enzymology, 505 (2012) 445-468.

[122] M. Formica, V. Fusi, L. Giorgi, M. Micheloni, New fluorescent chemosensors for metal ions in solution, Coord. Chem. Rev., 256 (2012) 170-192.

[123] Z. Liu, W. He, Z. Guo, Metal coordination in photoluminescent sensing, Chem. Soc. Rev., 42 (2013) 1568-1600.

[124] K.P. Carter, A.M. Young, A.E. Palmer, Fluorescent Sensors for Measuring Metal Ions in Living Systems, Chem. Rev., 114 (2014) 4564-4601.

[125] K. Sreenath, Z. Yuan, J.R. Allen, M.W. Davidson, L. Zhu, A Fluorescent Indicator for Imaging Lysosomal Zinc(II) with FRET-Enhanced Photostability and A Narrow Band of Emission, Chem. Eur. J., 21 (2015) 867-874.

[126] K. Sreenath, J.R. Allen, M.W. Davidson, L. Zhu, A FRET-Based Indicator for Imaging Mitochondrial Zinc Ions, Chem. Commun., 47 (2011) 11730-11732. 
[127] M.G.L. Gustafsson, Surpassing the lateral resolution limit by a factor of two using structured illumination microscopy, J. Microscopy, 198 (2000) 82-87.

[128] M.G.L. Gustafsson, L. Shao, P.M. Carlton, C.J.R. Wang, I.N. Golubovskaya, W.Z. Cande, D.A. Agard, J.W. Sedat, Three-Dimensional Resolution Doubling in Wide-Field Fluorescence Microscopy by Structured Illumination, Biophys. J., 94 (2008) 4957-4970. 
Graphical Abstract

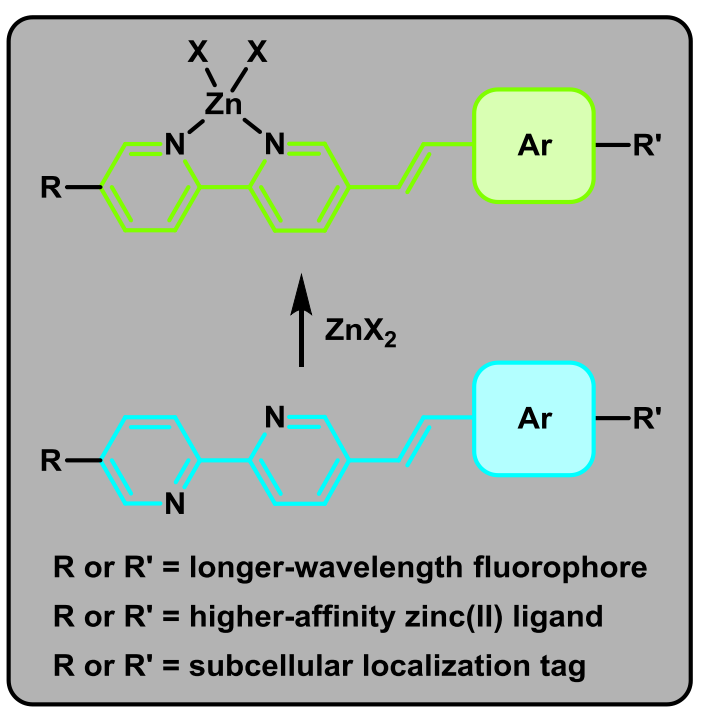


Cover Art

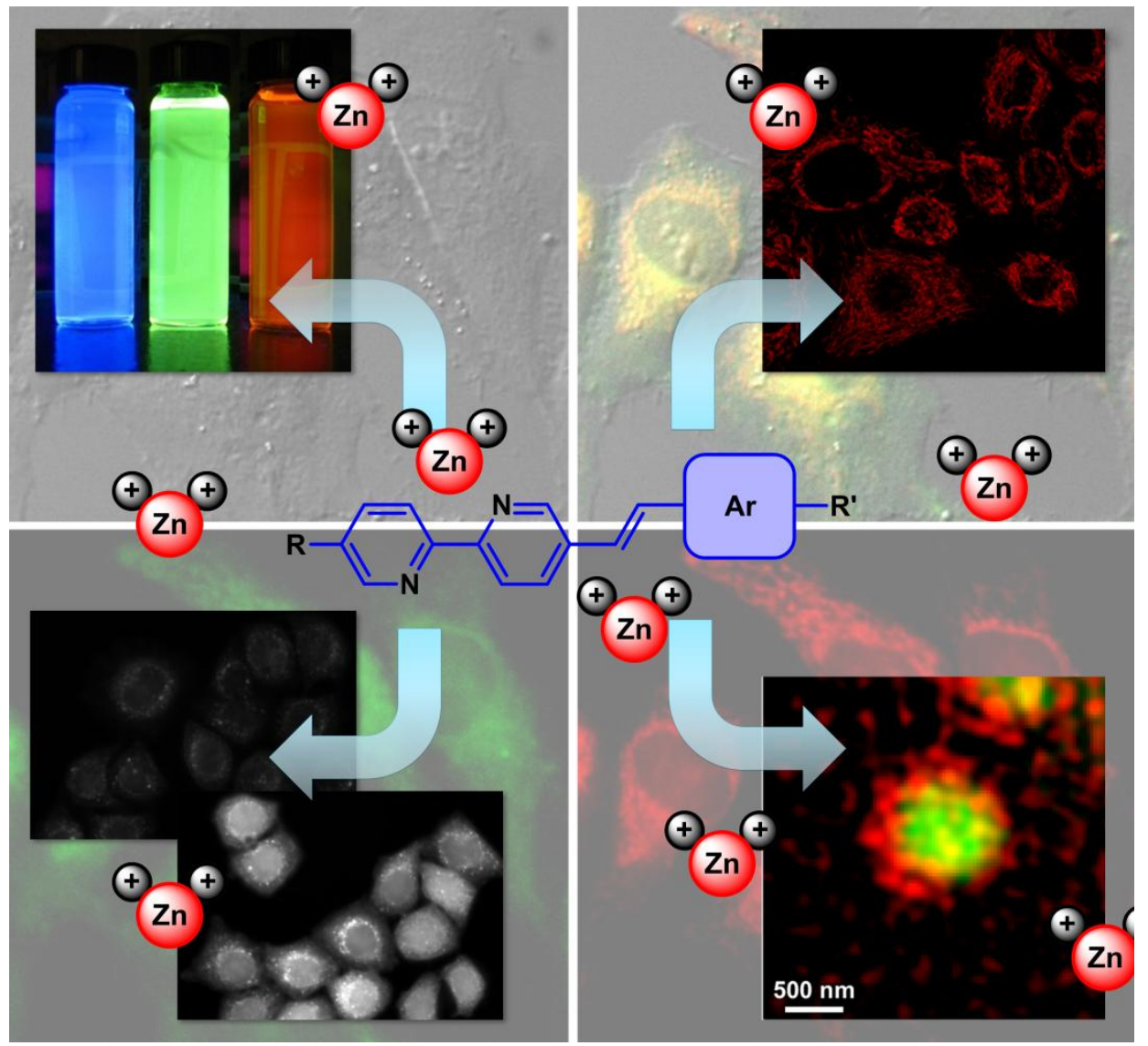

